Article

\title{
Enhanced Exopolysaccharide Production by Lactobacillus rhamnosus in Co-Culture with Saccharomyces cerevisiae
}

\author{
Annalisse Bertsch ${ }^{1,2,+}$, Denis Roy ${ }^{1,2}$ and Gisèle LaPointe ${ }^{3, *}$ (D) \\ 1 Department of Food Science, Pavillon Paul-Comtois, Office 1312, 2425 rue de l'Agriculture, Laval University, \\ Quebec City, QC G1V 0A6, Canada; bertscha@gmail.com (A.B.); denis.roy@fsaa.ulaval.ca (D.R.) \\ 2 Institute of Nutrition and Functional Foods (INAF), Pavillon des Services, 2440 Hochelaga Blvd, Laval \\ University, Quebec City, QC G1V 0A6, Canada \\ 3 Department of Food Science, University of Guelph, Guelph, ON N1G 2W1, Canada \\ * Correspondence: glapoint@uoguelph.ca \\ + The first author is presently employed by Biena, Saint-Hyacinthe, QC J2S 1L4, Canada.
}

Received: 1 August 2019; Accepted: 23 September 2019; Published: 26 September 2019

\begin{abstract}
Lactobacillus strains are known to produce exopolysaccharides (EPS) with recognized health benefits (i.e. prebiotic and immunomodulation) but production is limited by low yields. Co-culture has been shown to improve metabolite productivity, particularly bacteriocins and EPS. Although lactic acid bacteria (LAB) and yeasts are found in several fermented products, the molecular mechanisms linked to the microbial interactions and their influences on EPS biosynthesis are unclear. The aim of the present study was to investigate the effect of co-culture on EPS production by three Lactobacillus rhamnosus strains (ATCC 9595, R0011, and RW-9595M) in association with Saccharomyces cerevisiae. Fermentation, in both mono and co-culture, was carried out and the expression of key LAB genes was monitored. After $48 \mathrm{~h}$, results revealed that EPS production was enhanced by $39 \%$, $49 \%$, and $42 \%$ in co-culture for R0011, ATCC 9595, and RW-9595M, respectively. Each strain showed distinctive gene expression profiles. For a higher EPS production, higher EPS operon expression levels were observed for RW-9595M in co-culture. The construction of gene co-expression networks revealed common correlations between the expression of genes related to the EPS operons, sugar metabolism, and stress during EPS production and microbial growth for the three strains. Our findings provide insight into the positive influence of inter-kingdom interactions in stimulating EPS biosynthesis, representing progress toward the development of a bio-ingredient with broad industrial applications.
\end{abstract}

Keywords: exopolysaccharides; co-culture; whey permeate; yeast; lactic acid bacteria

\section{Introduction}

Exopolysaccharides (EPS) are biopolymers which are associated with the cell envelope or can be released into the external environment [1]. Bacterial EPS biosynthesis seems to be related to cell protection and abiotic/biotic stress [2-4]. They have strong potential to act as an immunoregulator, antioxidant, anti-hypertensive, anti-biofilm, cholesterol-lowering, or prebiotic agent [5-7]. However, reported low yields of EPS limit their production on a larger scale and there is a lack of clinical studies on the effective bio functionality of these polymers [8]. EPS have physicochemical properties that can enhance the sensorial and textural attributes of a variety of food and beverage products. Traditionally, lactic acid bacteria exopolysaccharides have an important role in fermented dairy products and more recently are being applied for the improvement of bakery products or gluten free products. Several studies reported that the use of EPS led to increased water absorption of the dough, better dough rheology and machinability, increased loaf volume, and decreased bread staling rate. The application 
of LAB EPS, when produced in situ, does not require labeling and therefore is seen as positive in an industry where consumers continually demand products containing less additives [5,7].

Obtaining bioingredients rich in microbial EPS is still a challenge. Alternatives to improve EPS production on a larger scale require more in-depth knowledge regarding EPS regulation and biosynthesis, optimizing fermentation conditions and formulating bacterial culture medium such as whey permeate [4] to valorize residual co-products of the agri-food industry, which can represent environmental and economic advantages [9].

Among other LAB, Lactobacillus rhamnosus strains are able to produce EPS. In particular, Lactobacillus rhamnosus R0011, Lactobacillus rhamnosus ATCC 9595, and Lactobacillus rhamnosus RW-9595M produce a range of quantities of the same exopolysaccharide [10]. This EPS is composed of a repetitive structure: a heptasaccharide containing glucose, galactose, and rhamnose in a 2:1:4 ratio and a pyruvate group [11]. Strain RW-9595M is the most productive of these three strains, with $543 \mathrm{mg} / \mathrm{L}$ of EPS without $\mathrm{pH}$ control and $1611-2775 \mathrm{mg} / \mathrm{L}$ in fermenters using whey permeate as the culture medium at controlled $\mathrm{pH} 6[12,13]$.

In biotechnology, co-culture has been shown to be more robust to environmental fluctuations and can perform more complex activities through the combination of metabolic capacities of different strains [14,15]. It is also an important tool to better understand microorganism physiology, provide interspecific or interkingdom (eukaryotes - prokaryotes) communication, and to discover new substances [16]. Mixed populations of yeast Saccharomyces cerevisiae and LAB are found together in numerous fermented products (kefir, kimchi, sourdough, wine, and cocoa), but the understanding of their interactions is still unclear $[17,18]$.

In the production of useful metabolites by LAB, the lactic acid must be removed to increase bacterial productivity and to enhance the economic feasibility of processes on an industrial scale $[19,20]$. A beneficial aspect of LAB-yeast association is the improvement of EPS production (kefiran) or bacteriocins (nisin), probably due to lactate consumption by the yeast in $\mathrm{pH}$-controlled culture [21-23]. Co-culture with S. cerevisiae supplied alanine to L. delbrueckii subspecies bulgaricus, enhanced the viability of L. rhamnosus $\mathrm{HN} 001$ under acidic conditions, and enhanced the tolerance of $L$. paracasei $\mathrm{H} 9$ to simulated gastrointestinal juices as well as adhesion to intestinal mucosa cells [24-26].

However, until now, no studies on LAB gene expression related to EPS biosynthesis in co-culture with S. cerevisiae have been reported under acidic conditions. The main objective of the present study was to determine the influence of co-culture of S. cerevisiae and three L. rhamnosus strains (ATCC 9595, R0011, and RW-9595M) on growth, viability, substrate bioconversion, and gene expression related to EPS biosynthesis during whey permeate fermentation without $\mathrm{pH}$ control.

\section{Materials and Methods}

\subsection{Strains and Media}

L. rhamnosus ATCC 9595 was purchased from the American Type Culture Collection (ATCC; Manassas, VA). L. rhamnosus RW-9595M and L. rhamnosus R0011 were obtained from our lactic acid bacteria culture collection (Université Laval, Quebec, Canada). The three strains of Lactobacillus rhamnosus were selected for their capacity to produce the same EPS composed of L-rhamnose, D-glucose and pyruvate-substituted D-galactose in a molar ratio of 4:2:1 [10,11]. The stock culture was kept frozen in $6 \%(v / v)$ rehydrated skim milk and $10 \%(v / v)$ glycerol at $-80{ }^{\circ} \mathrm{C}$. The baker's yeast Saccharomyces cerevisiae (Lallemand Instaferm Gold Instant dry yeast) was cultured on YEPAL solid medium (1\% yeast extract, $2 \%$ peptone, $1 \%$ lactic acid, and $2 \%$ Bacto agar).

Supplemented whey permeate (SWP) medium was composed of whey permeate supplemented with minerals, corn steep liquor, and yeast extract [13]. It was prepared as follows: Whey permeate powder (Agropur, Quebec) was rehydrated to give a final concentration of $5 \%(w / w) ; \mathrm{MgSO}_{4} \cdot 7 \mathrm{H}_{2} \mathrm{O}$, $\mathrm{MnSO}_{4} \cdot \mathrm{H}_{2} \mathrm{O}$, and Tween 80 were added to give final concentrations of $0.5 \mathrm{~g} / \mathrm{L}, 0.05 \mathrm{~g} / \mathrm{L}$, and $1 \mathrm{~mL} / \mathrm{L}$, respectively. The $\mathrm{pH}$ of the solution was adjusted to 4.9 with $6 \mathrm{~N} \mathrm{HCl}$ and then the solution was 
autoclaved $\left(121^{\circ} \mathrm{C}, 15 \mathrm{~min}\right)$, cooled to room temperature and filtered with a Whatman 42 filter. A concentrated corn steep liquor (CSL) was prepared by adding $25 \mathrm{~g}$ of CSL (Solulys 95, Roquette) to $100 \mathrm{~mL}$ deionized water. A concentrated yeast extract (YE) solution was prepared by adding $40 \mathrm{~g}$ of YE (Bacto Yeast extract) to $100 \mathrm{~mL}$ deionized water. These solutions were autoclaved $\left(121{ }^{\circ} \mathrm{C}\right.$, $15 \mathrm{~min}$ ) and added to whey permeate to give final concentrations of $1 \%$ and $1.5 \%(w / v)$, respectively in SWP medium.

\subsection{Mono- and Co-Culture Fermentation Experiments}

Fermentations were carried out in triplicate in 1-L bioreactors (Système quadruple automatisé; Biogénie, Québec, QC, Canada) containing SWP in monoculture fermentation experiments with the strains of L. rhamnosus and co-culture fermentation experiments with both lactic acid bacteria and yeast. After autoclaving the bioreactors at $121^{\circ} \mathrm{C}$ for $20 \mathrm{~min}$, the sterilized CLS and YE solutions were added aseptically [13]. Temperature and agitation of the bioreactors were controlled online and kept constant at $37^{\circ} \mathrm{C}$ and $200 \mathrm{rpm}$, respectively. The stock culture cells of L. rhamnosus were first inoculated into $10 \mathrm{~mL}$ of MRS and incubated at $37^{\circ} \mathrm{C}$ for $8 \mathrm{~h}$. Next, $50 \mathrm{~mL}$ of WP supplemented with yeast extract was inoculated at $2 \%(v / v)$ with the MRS culture and incubated at $37^{\circ} \mathrm{C}$ for $12 \mathrm{~h}$. A yeast colony from YEPAL agar was inoculated into $20 \mathrm{~mL}$ of YEPAL broth followed by incubation at $30^{\circ} \mathrm{C}$ in a shaker at $180 \mathrm{rpm}$ for $24 \mathrm{~h}$. The bioreactors were inoculated at $1 \%(v / v)$ with L. rhamnosus from the WP 12-h culture and S. cerevisiae from the $24 \mathrm{~h}$ YEPAL culture. Samples of the bioreactor culture broth were taken after $0 \mathrm{~h}, 3 \mathrm{~h}, 6 \mathrm{~h}, 9 \mathrm{~h}, 12 \mathrm{~h}, 15 \mathrm{~h}, 24 \mathrm{~h}$, and $48 \mathrm{~h}$ of fermentation.

\subsection{Monitoring of Bacterial Growth}

The concentrations of cells were determined in samples taken during mono- and co-culture by:

(i) Plate count determination

Viable (cultivable) Lactobacilli or yeast counts were determined by spread-plating 10-fold serial dilutions (in $0.1 \%, w / v$, sterilized peptone water) on MRS agar (de Mann, Rogosa and Sharpe agar is selective for Lactobacillus due to lack of lactose consumption by yeast) or on YEPAL agar (selective for $S$. cerevisiae due to lack of consumption of lactic acid by Lactobacillus), and incubated aerobically at $37^{\circ} \mathrm{C}$ and $30^{\circ} \mathrm{C}$ for $48 \mathrm{~h}$ for lactic acid bacteria strains and the yeast, respectively. The viable (cultivable) counts were expressed as the number of colony-forming units (CFU) per $\mathrm{mL}$.

(ii) qPCR (total cells) and PMA-qPCR (viable cells) analysis

To distinguish viable from dead cells of L. rhamnosus, qPCR in combination with propidium monoazide (PMA) (PMA-qPCR) was used to determine the log of total cells (qPCR) or viable cells per $\mathrm{mL}$ (PMA-qPCR). As PMA is cell membrane-impermeable, it only covalently binds, after photoactivation, to double-stranded DNA of damaged cells and will inhibit DNA amplification during qPCR $[27,28]$. Samples taken were immediately diluted 1:10 with peptone water $(1 \mathrm{~g} / \mathrm{L}$ BactoPeptone and $0.5 \mathrm{~g} / \mathrm{L}$ $\mathrm{NaCl}$ ). For the PMA-qPCR analyses, the diluted samples were treated with $50 \mu \mathrm{M}$ PMA (Biotium, Hayward, CA, USA) and incubated in the dark at room temperature for 5 min while gently being shaken. Next, the PMA-treated cell suspensions were placed in an LED-Active Blue system (Ingenia Bio- systems, Barcelona, Spain) for $15 \mathrm{~min}$ and centrifuged at $15,000 \times \mathrm{g}$ for $20 \mathrm{~min}$ at $4{ }^{\circ} \mathrm{C}$. Samples not treated with PMA were centrifuged immediately after dilution at $15,000 \times g$ for $20 \mathrm{~min}$ at $4{ }^{\circ} \mathrm{C}$. Cell pellets were stored at $-80^{\circ} \mathrm{C}$ until DNA extraction.

Genomic DNA (gDNA) was extracted using the DNeasy Blood and Tissue kit (Qiagen, Mississauga, ON, Canada) with minor modifications of the manufacturer's protocol for Gram-positive bacteria (Qiagen): $2.5 \mu \mathrm{L} / \mathrm{mL}$ mutanolysin (20 U/mL; Sigma-Aldrich) was added to the lysis buffer and an additional incubation with DNase-free RNase (Roche, Laval, QC, Canada) was performed at $37^{\circ} \mathrm{C}$ for $60 \mathrm{~min}$ according to the manufacturer's instructions. The extracted gDNA was stored at $-20^{\circ} \mathrm{C}$ until qPCR amplification. 
Primers for qPCR targeting the tuf gene in L. rhamnosus (Table S1 in the supplemental material) were designed with Geneious Pro 5.3 (Biomatters, Auckland, New Zealand) on the basis of the complete genome sequence of L. rhamnosus R0011 and the EPS gene cluster of the strains of L. rhamnosus R0011, ATCC9595, and RW-9595M (National Center for Biotechnology Information [NCBI; NCBI Resource Coordinators, 2015] database accession numbers NZ_AGKC00000000 and AY659978.1; AY659976.1; AY659979.1, respectively). With the same software, the presence of hairpins, self-dimers, and pair-dimers was checked. The primers were synthesized by Integrated DNA Technologies (Coralville, IA, USA). Gene- and strain-specificity of the primers was confirmed in silico by Primer-Blast and by qPCR analysis on gDNA of both strains (the cycle threshold value [Ct] was undetermined for $S$. cerevisiae (Table S1 due to lack of amplification) [29]. qPCR was performed using a 7500 Fast Real-Time PCR system (Applied Biosystems, Carlsbad, CA, USA) with 96-well plates. Each PCR reaction mixture of $20 \mu \mathrm{L}$ contained $10 \mu \mathrm{L}$ of Fast SYBR Green Master Mix (Life Technologies, Burlington, ON, Canada), $1 \mu \mathrm{L}$ of the extracted gDNA, $1 \mu \mathrm{L}$ of each primer at their optimal concentrations (Table S1), and $8 \mu \mathrm{L}$ of sterile nuclease-free water (Qiagen). The qPCR amplification program consisted of an initial denaturation step at $95{ }^{\circ} \mathrm{C}$ for $20 \mathrm{~s}$, followed by 40 two-step cycles at $95^{\circ} \mathrm{C}$ for $3 \mathrm{~s}$ and at $60{ }^{\circ} \mathrm{C}$ for $30 \mathrm{~s}$. In each run negative (without gDNA) and positive controls (known gDNA) were run for the two primers sets. After each amplification run, the specificity of the primer sets of each PCR product was controlled by checking the melting curves. The $\mathrm{Ct}$ values were determined using the 7500 software (v2.0.6; Applied Biosystems) after taking the average of the automatic thresholds for each primer set and using this average for all qPCR runs. All qPCR amplifications were performed in triplicate [28].

Finally, the log of the total cells $/ \mathrm{mL}$ or viable cells $/ \mathrm{mL}$ of the L. rhamnosus strains during monoand co-culture fermentations were calculated from the $\mathrm{Ct}$ values using the corresponding standard curve $[27,28]$. The standard curve and detection limit were determined using a pure culture of each strain of L. rhamnosus. One $\mathrm{mL}$ of culture was serially diluted eight times in sterile culture medium. Next, $1 \mathrm{~mL}$ of each dilution was treated with PMA as described above. DNA extraction and quantification were performed as for the fermentation samples.

\subsection{Monitoring of Sugar Consumption and Metabolite Production}

Samples taken during fermentation were immediately centrifuged at $5000 \times g$ for 20 min at $4{ }^{\circ} \mathrm{C}$ and stored at $-20^{\circ} \mathrm{C}$ until analysis.

(i) Determination of sugars, organic acids and ethanol

Lactose, acetate, ethanol, and lactate concentrations were determined through HPLC with a Waters chromatograph (Waters, Milford, MA, USA), equipped with a Hitachi (Foster City California, USA) differential refractive index (RI) detector (L-7490), 600E controller, column oven $\left(40^{\circ} \mathrm{C}\right)$, and cooled 717 Plus autosampler. An ICSep ION-300 column (Transgenomic, Omaha, NE, USA) was used with an 8.5- $\mathrm{mM} \mathrm{H}_{2} \mathrm{SO}_{4}$ solution as the mobile phase at a flow rate of $0.4 \mathrm{~mL} / \mathrm{min}$. Samples were diluted two-thirds with Milli-Q water, centrifuged at 20,000 $\mathrm{g}$ for $15 \mathrm{~min}$ at $4{ }^{\circ} \mathrm{C}$, and filtered (pore size of $0.45 \mu \mathrm{m}$; Chromspec Syringe Filter; Chromatographic Specialties, Brockville, ON, Canada) before injection $(15 \mu \mathrm{L})$. A mixture of acetate, lactate (Sigma-Aldrich), and ethanol (JT Baker Chemical) was used as an external standard to perform quantifications. All samples were analyzed in triplicate.

\section{(ii) Exopolysaccharide determination}

EPS isolation and purification were carried out by ethanol precipitation, as described previously [30] with a few modifications. Samples were heated for $15 \mathrm{~min}$ at $100{ }^{\circ} \mathrm{C}$, then cells were eliminated by centrifugation at $12,000 \times \mathrm{g}$ for $45 \mathrm{~min}$ at $4{ }^{\circ} \mathrm{C}$. EPS were precipitated from the supernatant with 3 volumes $95 \%$ ethanol at $4{ }^{\circ} \mathrm{C}$ for $16 \mathrm{~h}$, and collected by centrifugation at $12,000 \times g$ for $20 \mathrm{~min}$. EPS pellets were dissolved in deionized water and dialyzed over a period of 2 days at $4{ }^{\circ} \mathrm{C}$, with two water changes per day, and the dialysate was lyophilized. The crude EPS was further purified by dissolving it in 10\% trichloroacetic acid, and the precipitate was washed twice in 
order to recover the total polymer. After dialysis for 3 days, with two changes of water per day, the solution was freeze-dried. Total sugars were measured by the phenol/sulfuric acid method [31], with glucose as a standard, and the results are expressed in mg glucose L-1. The SWP medium without inoculation was used as control. The blank value of unfermented SWP medium was subtracted from the EPS concentrations.

(iii) Determination of phenolic compounds

The UPLC analysis of the phenolic acids was performed using a Waters Acquity Ultra-Performance TM LC system (Waters), equipped with a quaternary pump system (Waters). The Acquity high-strength silica (HSS) T3 column (150 mm $2.1 \mathrm{~mm}$ id, $1.8 \mathrm{~mm}$ particle size) from Waters was used. The stationary phase was $100 \%$ silica particles. The phenolic acids were separated with a mobile phase that consisted of $0.1 \%$ Formic acid (eluent $\mathrm{A}$ ) and acetonitrile (eluent $\mathrm{B}$ ), The flow-rate was $0.4 \mathrm{~mL} / \mathrm{min}$ and the gradient elution was initial, $5 \% \mathrm{~B} ; 0-4.5 \mathrm{~min}, 5 \%-20 \% \mathrm{~B} ; 4.5-6.45 \mathrm{~min}$, isocratic $20 \% \mathrm{~B} ; 6.45-13.5 \mathrm{~min}$, $20 \%-45 \% \mathrm{~B} ; 13.5-16.5 \mathrm{~min} 45 \%-100 \% \mathrm{~B} ; 16.5-19.5 \mathrm{~min}$ isocratic $100 \% \mathrm{~B} ; 19.5-19.52 \mathrm{~min} 5 \%-100 \% \mathrm{~B}$; $19.52-22.5 \mathrm{~min}$ isocratic $5 \% \mathrm{~B}$. The analyses were carried out on a TQD mass spectrometer (Waters) equipped with a Z-spray electrospray interface. The analysis was performed in negative mode and the data was acquired through multiple reactions monitoring (MRM). The ionization source parameters were capillary voltage, $2.75 \mathrm{kV}$; source temperature, $140^{\circ} \mathrm{C}$; cone gas flow rate, $80 \mathrm{~L} / \mathrm{h}$ and desolvation gas flow rate, $900 \mathrm{~L} / \mathrm{h}$; desolvation temperature, $350{ }^{\circ} \mathrm{C}$. Nitrogen ( $99 \%$ purity) and argon ( $99 \%$ purity) were used as nebulizing and collision gases, respectively. Data acquisition was carried out with the Mass Lynx 4.1 software.

\subsection{Relative Gene Expression}

Relative expression of genes involved in carbohydrate metabolism, EPS operons, amino acid transport, lipid metabolism, stress and cellular responses and other functions (microbial metabolism in diverse environments) (see Table S1-S3 in the supplemental material) in L. rhamnosus R0011, $L$. rhamnosus ATCC 9595 and L. rhamnosus RW-9595M during co-culture fermentation with S. cerevisiae was studied after $6,9,12,15$, and $24 \mathrm{~h}$ of fermentation, representing exponential (mid and late) and stationary growth phases. The co-culture was compared to the control fermentation (monoculture fermentations with L. rhamnosus R0011, L. rhamnosus ATCC 9595, or L. rhamnosus RW-9595M). The protocol has been established in accordance with good practice (MIQE) in gene expression experiments by RT-qPCR [32].

(i) Primer and probe design

TaqMan gene expression assays (containing both primers and probes) were manually designed with Geneious Pro 5.3 for 40 target genes and for six reference genes based on the complete genome sequences of L. rhamnosus R0011 and the EPS gene clusters of L. rhamnosus R, ATCC 9595, and RW-9595M (NCBI). Putative gene functions were obtained from the NCBI database and from the pathway databases BioCyc and Genomes (KEGG) (NCBI Resource Coordinators, 2015) (December 2015, Tables S1 to S34). With Geneious Pro 5.3 the presence of hairpins, self-dimers, and pair-dimers in the TaqMan gene expression assays was predicted. The TaqMan gene expression assays were synthesized by Life Technologies. The PCR amplification was simulated with both primers (http://insilico.ehu.es/PCR/). To confirm gene- and strain-specificity of the TaqMan gene expression assays, qPCR amplification was simulated in silico by Primer-Blast [29] and performed on genomic DNA of both strains (Ct results were at least $10 \mathrm{Ct}$ higher for the strains of L. rhamnosus, respectively; Table S2) [28].

\section{(ii) RNA extraction}

Samples $(300 \mu \mathrm{L})$ were taken of mono- and co-culture fermentations of the three strains of $L$. rhamnosus and immediately treated with RNAprotect Bacteria Reagent (Qiagen) according to the manufacturer's instructions. The cell pellets were stored at $-80^{\circ} \mathrm{C}$ until RNA extraction. Total RNA 
was extracted using the RNeasy Mini kit (Qiagen), with minor modifications of the manufacturer's RNA protect Bacteria Reagent protocol (Qiagen). The cell pellets were suspended in $100 \mu \mathrm{L}$ (RNeasy Mini kit) TE buffer (30 mM Tris base, $1 \mathrm{mM}$ EDTA, pH 8.0) containing $20 \mathrm{mg} / \mathrm{mL}$ lysozyme (Sigma-Aldrich), $10 \mu \mathrm{L}$ proteinase $\mathrm{K}(20 \mathrm{mg} / \mathrm{mL}$, Sigma-Aldrich), and $10 \mu \mathrm{L}$ mutanolysin (20 U/mL; Sigma-Aldrich) and were incubated at $37^{\circ} \mathrm{C}$ for $60 \mathrm{~min}$. After the addition of $700 \mu \mathrm{L}$ (RNeasy Mini kit) of RLT buffer, cell suspensions were transferred to sterile tubes containing $50 \mathrm{mg}$ of zirconium beads $(0.5 \mathrm{~mm}$; Biospec Products, Bartlesville, OK, USA), shaken three times at high intensity for $60 \mathrm{~s}$ in a Bead Ruptor (Omni International), and centrifuged at maximum speed for $20 \mathrm{~s}$ to remove cell debris. DNA was removed during RNA isolation by performing an on-column RNase-free DNase I (Qiagen) treatment according to the manufacturer's instructions. After elution of RNA with $50 \mu \mathrm{L}$ (RNeasy Mini kit) of RNase-free water, $2 \mu \mathrm{L}$ (RNeasy Mini kit) of Protector RNase inhibitor (40 U/ $\mu \mathrm{L}$; Roche) was added and a second RNase-free DNase I treatment ( $3 \mu \mathrm{L}$ Dnase I [10 U/ $\mu \mathrm{L}$; Roche) was performed for $30 \mathrm{~min}$ at $37^{\circ} \mathrm{C}$. DNase I was inactivated by adding $2 \mu \mathrm{L}$ of EDTA $(25 \mathrm{mM})$ to the reaction mixture and heating at $65^{\circ} \mathrm{C}$ for $15 \mathrm{~min}$. The absence of DNA in the RNA samples was verified by qPCR using the tuf primers designed for the strains of L. rhamnosus (Table S1). RNA quality (RNA quality control RNA integrity number [RIN]) and quantity were determined using an Agilent 2100 Bioanalyzer (Agilent Technologies, Santa Clara, CA, USA). All extracted RNA was of good quality and RIN varied between 8.3 and 10.0 (with an average RIN of $9.5 \pm 0.4$ ).

\section{(iii) Monitoring of gene expression}

Total RNA ( $50 \mathrm{ng} / \mu \mathrm{L}$ ) was reverse transcribed to cDNA in a final volume of $100 \mu \mathrm{L}$ with the High Capacity cDNA Reverse Transcription kit with RNase Inhibitor (Applied Biosystems) according to the manufacturer's instructions using a TProfessional Basic Gradient thermocycler at $25^{\circ} \mathrm{C}$ for $10 \mathrm{~min}$, $37^{\circ} \mathrm{C}$ for $120 \mathrm{~min}$, and $85^{\circ} \mathrm{C}$ for $5 \mathrm{~min}$. cDNA samples were stored at $-20^{\circ} \mathrm{C}$ for RT-qPCR analysis and the remaining RNA was stored at $-80^{\circ} \mathrm{C}$.

A qPCR based on TaqMan fluorescence was performed using a Vii ${ }^{\mathrm{TM}}$ A7 Real-Time PCR System (Applied Biosystems) with 384-well plates. Each PCR reaction mixture of $10 \mu \mathrm{L}$ contained $5 \mu \mathrm{L}$ TaqMan Fast Advanced Master Mix (Life Technologies), $4 \mu \mathrm{L}$ of the 2.5X TaqMan designed Gene Expression Assay Mix (containing both primers and TaqMan probe), and $1 \mu \mathrm{L}$ of cDNA. The qPCR amplification program consisted of an initial denaturation step at $95^{\circ} \mathrm{C}$ for $20 \mathrm{~s}$, followed by 40 two-step cycles at $95^{\circ} \mathrm{C}$ for $1 \mathrm{~s}$ and at $60^{\circ} \mathrm{C}$ for $20 \mathrm{~s}$. In each run negative (without cDNA) and positive controls (with known gDNA) were included. The Ct values were determined using the Vii ${ }^{\mathrm{TM}} \mathrm{A} 7$ software (Applied Biosystems) after taking the average of the automatic thresholds for each primer set and using this average for all qPCR runs. All qPCR amplifications were performed in triplicate.

\section{(iv) Relative quantification of gene expression levels}

The relative (co-culture fermentations relative to monoculture fermentations) expression ratio of each target gene in relation to multiple reference genes was calculated by an efficiency-corrected relative quantification methodology by the REST 2009 software [33] (Qiagen) (2004) for each time point (6 h, 9 h, 12 h, 15 h, and 24 h) for L. rhamnosus R0011, L. rhamnosus ATCC 9595, and L. rhamnosus RW 9595M. Briefly, this method first transforms the $\mathrm{Ct}$ values of each target gene during co-culture fermentation into expression values using $\mathrm{E}^{\mathrm{Ct}}$, where $\mathrm{E}$ is the PCR amplification efficiency, and divides this value by the corresponding $\mathrm{E}^{\mathrm{Ct} \text {,control }}$ value for the same target gene in the control sample (monoculture fermentation) to obtain $\mathrm{E}^{\Delta \mathrm{Ct}}$. In a next step, the relative expression ratio is determined by dividing the ratio $\left(\mathrm{E}^{\Delta \mathrm{Ct}}\right)$ by a normalization factor, which is the geometric mean of the $\mathrm{E}^{\Delta \mathrm{Ct}}$ values of the most stable reference genes. The $\mathrm{E}$ value for each TaqMan gene expression assay (target genes and reference genes) was determined by performing qPCR reactions of a 5-log dilution range of gDNA and plotting the logarithm of the gDNA concentrations as a linear function of the Ct values [26]. From the slope of each standard curve, E was calculated as follows: The efficiencies of the TaqMan gene expression assays varied between 1.81 and 2.04 (Table S2). The Ct cut-off value (highest allowed Ct value) was set 
at 32 as it was found that above this value the $\mathrm{Ct}$ values did not fit the standard curve. The software geNorm [33] was used to identify which reference genes out of six candidate genes for each strain of Lactobacillus were the most stable for each time point in this experimental set-up (Table S3).

\subsection{Statistical Analyses}

The results of growth, viability, $\mathrm{pH}$, and metabolite production were calculated as means of at least three replicate values. The data were analyzed by one-way ANOVA. The statistics were carried out with GraphPad Prism 6 (GraphPad software). The fermentation data was analyzed through Principal Component Analysis (PCA), using the software Statgraph Centurion VII. A Pearson correlation test $(r)$ was conducted to determine correlations between the variables.

Statistical significance of the calculated gene expression ratios (RER) was determined by REST 2009 using a Pair Wise Fixed Reallocation Randomization Test [34] with 2000 permutations to determine whether the observed effects are the result of the co-culturing of each strain of L. rhamnosus or by chance only, with p-values less than 0.05 considered statistically significant. Gene expression corresponding to a negative relative expression ratio is further referred to as underexpression, whereas gene expression corresponding to a positive RER is further referred to as overexpression in relation to monoculture condition.

Cytoscape (version 3.4.0) was used to sort through and visualize the correlations generated to create networks showing the gene co-expression of 34 genes for each strain [35]. Two network topology characteristics for the network were calculated using Network Analyzer in Cytoscape: a) the Betweenness centrality (BC) of a node reflects the amount of control that this node exerts over the interactions of other nodes in the network. The more a node is included in shortest paths between any two other nodes, the higher its betweenness centrality (values near to 1) is within this network; b) Degree distribution, the node degree of a node $n$ is the number of edges linked to $n$. These two parameters are frequently used to identify nodes for which the disruption could greatly affect a network response [35-37].

\section{Results}

\subsection{Co-culture of Lactobacillus Rhamnosus Strains and Saccharomyces Cerevisiae}

(i) Effect of co-cultivation on bacterial growth

The growth curves of three L. rhamnosus strains showed the same pattern in monoculture as in co-culture with S. cerevisiae (Figure 1A,D,G). Viable cell counts $(\mathrm{CFU} / \mathrm{mL})$ revealed a stationary growth phase after $9 \mathrm{~h}$ for L. rhamnosus strains ATCC 9595 (Figure 1D) and RW-9595M (Figure 1G), and $12 \mathrm{~h}$ for L. rhamnosus R0011 (Figure 1A). The quantification in genome copy numbers of L. rhamnosus ATCC 9595 obtained by PMA-qPCR were lower than those obtained by qPCR, indicating the presence of dead cells, especially in co-culture, with $95 \%$ viability. Nevertheless, as for the other strains, plate counts did not decrease during fermentation (Figure 1E,F). These results indicate that viability of targeted strains persisted in mono- and co-culture, despite the media culture acidity until $48 \mathrm{~h}(\mathrm{pH}<3.5)$. 

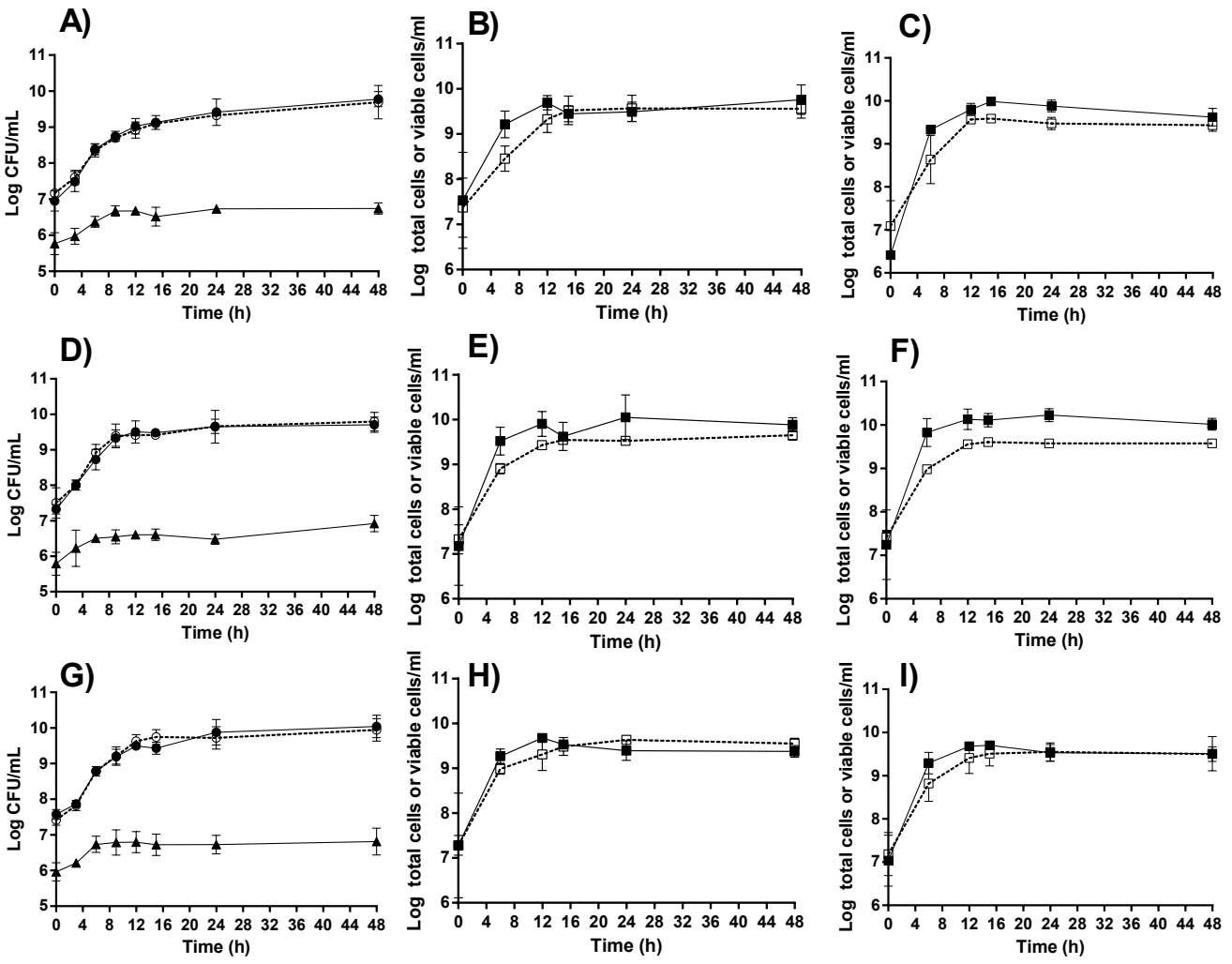

Figure 1. Growth of L. rhamnosus strains in mono (-; solid line) and co-culture (-○-; dashed line) with S. cerevisiae $(\Delta)$. The cell concentrations were determined by viable cultivable counts expressed as

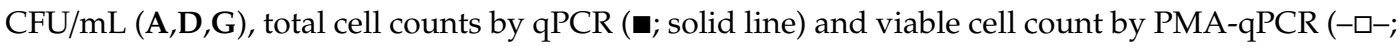
dashed line) expressed as cells/mL for mono $(\mathbf{B}, \mathbf{E}, \mathbf{H})$ and co-culture $(\mathbf{C}, \mathbf{F}, \mathbf{I})$ by Lactobacillus rhamnosus R0011 (A-C), ATCC 9595 (D-F) and RW-9595M (G-I), respectively. The values are the average of triplicate fermentations and error bars represent the standard error.

(ii) Effect of co-culture on sugar consumption and metabolite production

Differences in sugar consumption and metabolite production were found between the monoculture and co-culture fermentations (Figure 2A-F). In monoculture fermentation, lactose consumption by L. rhamnosus ATCC 9595 was significantly higher $(\mathrm{p}<0.05)$ in relation to co-culture. However, the amount of lactic acid detected was the same in both types of culture (Figure 2A-C). Comparison of the conversion rates of lactose to lactic acid by L. rhamnosus RW-9595M and R0011 in mono and co-culture showed no significant differences $(\mathrm{p}<0.05)$.

L. rhamnosus R0011 produced $1.8 \mathrm{~g} / \mathrm{L}$ less lactic acid than the other strains at the end of the process due to a lower lactose consumption. Throughout fermentation, $\mathrm{pH}$ values for co-culture with L. rhamnosus R0011 were 5\% and 2.7\% higher than the $\mathrm{pH}$ values of RW-9595M and ATCC 9595, respectively (Supplemental Figure S1).

After $24 \mathrm{~h}$ of fermentation, the presence of acetic acid was observed in media. Acetic acid concentrations in culture broth were significantly $(\mathrm{p}<0.05)$ superior in monoculture (Supplemental Figure S2) compared to co-culture for L. rhamnosus ATCC 9595 (54\%) and RW-9595M (38\%). L. rhamnosus R0011 did not show any difference between culture types for acetic acid concentration.

Additionally, the content of phenolic acids from corn steep liquor such as ferulic acid, 4-hydroxybenzoic acid, caffeic acid, and p-coumaric acid, were determined [38]. After $48 \mathrm{~h}$ of fermentation, the profile of phenolic acids was modified by the L. rhamnosus strains. Ferulic acid decreased while caffeic acid increased and protocatechuic acid appeared in culture broth (Supplemental Table S4). The phenolic acid profile for yeast monoculture did not show any difference compared to non-fermented medium; therefore, this activity was linked to LAB (data not shown). 

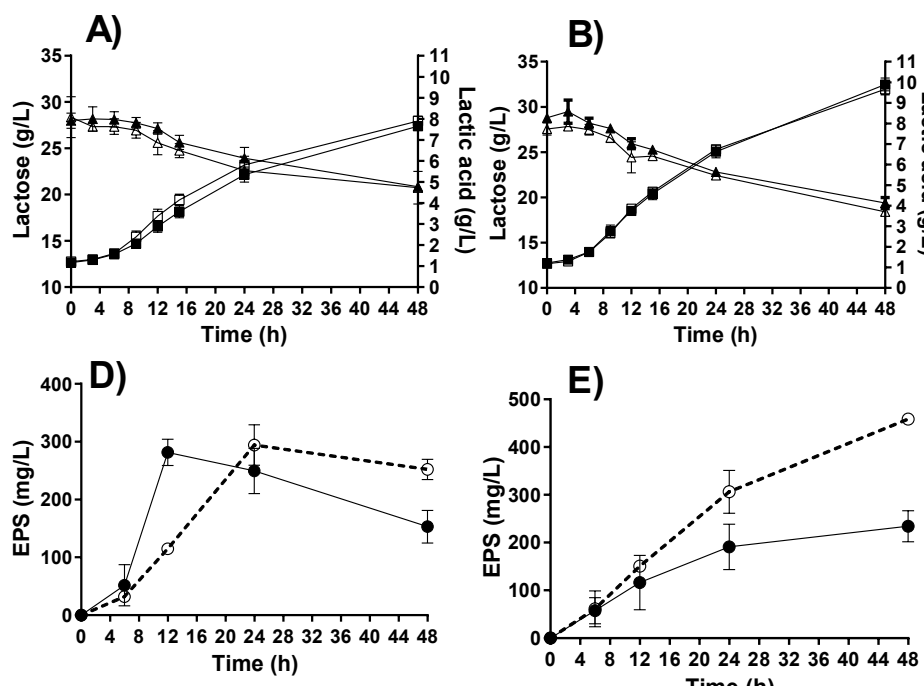

E)

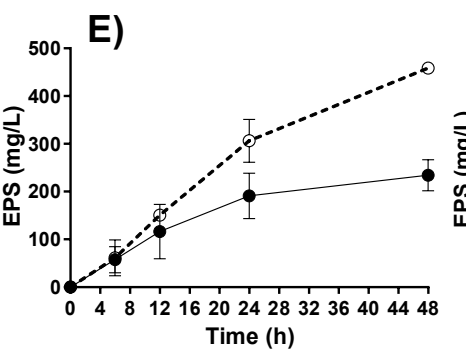

C)

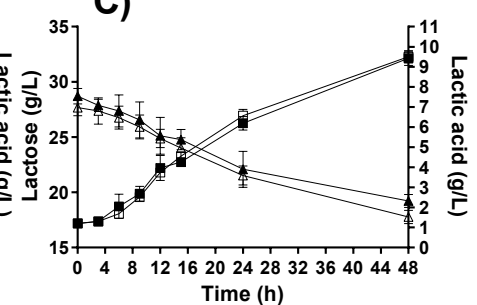

F)

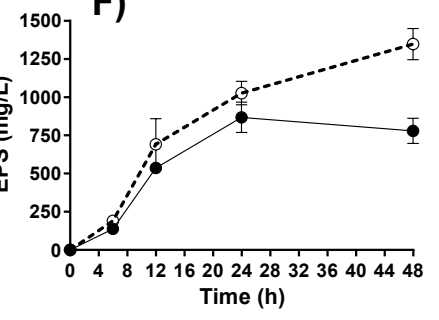

Figure 2. Lactose consumption $(\Delta \mathbf{\Lambda})$, lactic acid $(\square \mathbf{\square})$ and exopolysaccharide $(\bigcirc \bullet)$ production by L. rhamnosus R0011 (A,D); ATCC 9595 (B,E) and RW-9595M (C,F) in mono (solid symbols) and co-culture (open symbols). The values are the average of three fermentations and the bars represent the standard error.

(iii) Effect of co-culture on exopolysaccharide (EPS) production

Exopolysaccharide production was modified between monoculture and co-culture for all tested strains (Figure 2D-F). The L. rhamnosus R0011 strain had a 12-hour delay to maximal EPS concentration in co-culture compared to monoculture. After 48 hours, EPS concentration was higher in co-culture $(99 \mathrm{mg} / \mathrm{L} ; 39 \%$ ) for strain R0011, but along the entire process, total EPS production was similar to that obtained in monoculture. In contrast, for L. rhamnosus ATCC 9595 and RW-9595M, EPS production in co-culture was significantly different $(\mathrm{p}<0.05)$ from monoculture after the 48-hour fermentation period, with an increase of $49 \%(224 \mathrm{mg} / \mathrm{L})$ and $42 \%(568 \mathrm{mg} / \mathrm{L})$, respectively. Strain RW-9595M showed a production of EPS $81 \%(1095 \mathrm{mg} / \mathrm{L})$ and $66 \%(888 \mathrm{mg} / \mathrm{L})$ higher than strains R0011 and ATCC 9595, respectively. Co-culture appears to have a positive effect on EPS production, even under acid stress.

Principal Component Analysis (PCA) was carried out on the combined data for all three $L$. rhamnosus strains in mono and co-culture. For each strain, significant correlations $(\mathrm{p}<0.05)$ showed that in all cases two variables explained 70\% of total variance (Figure 3D-F). EPS production was principally associated with growth and with lactic acid production for L. rhamnosus strains. It was determined that lactose and $\mathrm{pH}$ were negatively correlated with EPS production for the strains.
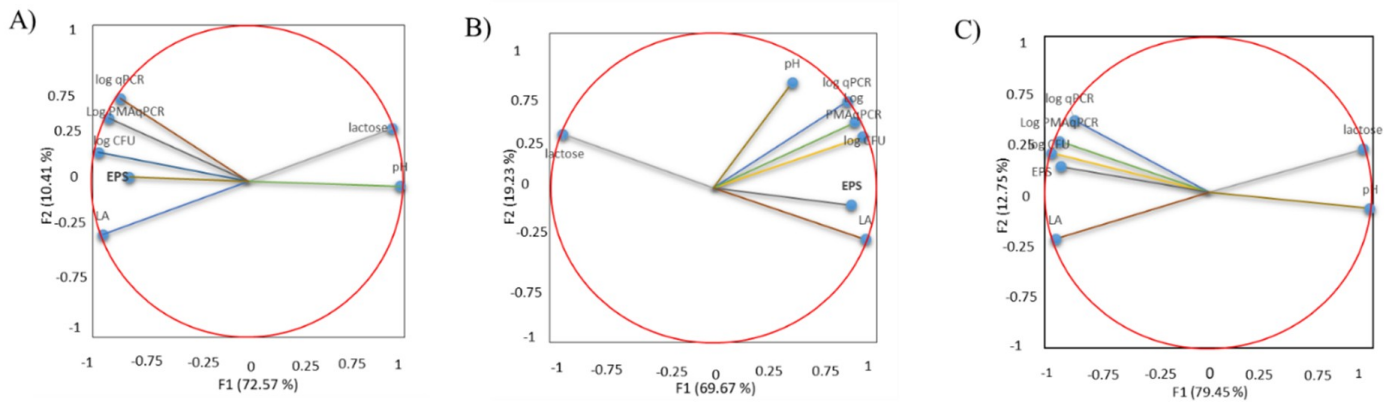

Figure 3. Principal component analysis (PCA) on the basis of growth, viability, $\mathrm{pH}$, sugar consumption, lactic acid and exopolysaccharide production for L. rhamnosus R0011 (A); ATCC 9595 (B) and RW-9595M (C). Log CFU = viable cultivable counts in CFU/mL, log qPCR = total counts by qPCR and log PMA-qPCR = by PMA-qPCR in viable cells $/ \mathrm{mL}$; lactose, $\mathrm{LA}=$ lactic acid; $\mathrm{pH}$ and exopolysaccharides $=$ EPS. 


\subsection{Analysis of Relative Gene Expression in Co-Culture}

Statistical analyses indicate significant differences in the relative gene expression ratio (RER) in co-culture compared to the control (monoculture) for all three strains (Tables 1-3 and Figure 4A-C). The RER varied from -4.35 to 7.75 for R0011; -21.74 to +17.29 for ATCC 9595 and -30.3 to +11.191 for RW-9595M. In co-culture compared to monoculture, L. rhamnosus R0011 and RW-9595M had more over-expressed genes (67\% and 71\%) than under-expressed genes (33\% and 29\%). For the ATCC 9595 strain, the proportion of over-expressed genes ( $42 \%)$ was lower than under-expressed genes $(58 \%)$. L. rhamnosus RW-9595M was the strain with the highest number of genes influenced by S. cerevisiae during co-culture fermentation. In general for all the strains, the target gene expression in co-culture was under-expressed at the end of the fermentation process compared to monoculture.

Table 1. Relative expression ratio (RER) of genes involved in carbohydrate catabolism, EPS operons, amino acid biosynthesis and lipid metabolism, stress and cellular responses and other functions (microbial metabolism in diverse environments) of L. rhamnosus R0011 over 24 h during growth in whey permeate in co-culture with S. cerevisiae.

\begin{tabular}{|c|c|c|c|c|c|c|c|c|c|c|c|}
\hline \multirow[b]{3}{*}{ Metabolic pathway } & \multirow[b]{3}{*}{ Gene $^{a}$} & & & \multicolumn{8}{|c|}{ Fermentation Time } \\
\hline & & \multicolumn{2}{|c|}{$6 \mathrm{~h}$} & \multicolumn{2}{|c|}{$9 \mathrm{~h}$} & \multicolumn{2}{|c|}{$12 \mathrm{~h}$} & \multicolumn{2}{|c|}{$15 \mathrm{~h}$} & \multicolumn{2}{|c|}{$24 \mathrm{~h}$} \\
\hline & & RER $^{b}$ & $P^{\mathrm{c}}$ & RER $^{b}$ & $P^{\mathrm{c}}$ & RER $^{b}$ & $P^{\mathrm{c}}$ & RER $^{b}$ & $P^{\mathrm{c}}$ & RER $^{b}$ & $P^{\mathrm{c}}$ \\
\hline \multirow{8}{*}{$\begin{array}{l}\text { Carbohydrate catabolism } \\
\text { (G1) }\end{array}$} & galk & -1.339 & 0.217 & 1.004 & 0.978 & 1.437 & 0.396 & -1.563 & 0.309 & -2.0457 & 0.000 \\
\hline & $\operatorname{bgaC}$ & 7.754 & 0.000 & -1.339 & 0.441 & 4.294 & 0.000 & 1.498 & 0.048 & -1.905 & 0.007 \\
\hline & gale & -1.552 & 0.248 & 1.078 & 0.897 & 1.144 & 0.527 & -3.195 & 0.234 & -1.267 & 0.596 \\
\hline & $\operatorname{lac} T$ & 1.924 & 0.000 & 1.012 & 0.975 & 2.050 & 0.041 & -1.323 & 0.535 & 1.123 & 0.677 \\
\hline & galR & 2.383 & 0.001 & -1.151 & 0.678 & 2.733 & 0.002 & 1.244 & 0.625 & -1.316 & 0.197 \\
\hline & lacD & 1.371 & 0.108 & -1.163 & 0.758 & 2.358 & 0.007 & 1.101 & 0.797 & 1.115 & 0.546 \\
\hline & acka & 1.821 & 0.089 & -1.053 & 0.899 & 2.390 & 0.015 & -1.043 & 0.896 & 1.813 & 0.012 \\
\hline & pyK & 1.582 & 0.000 & 3.691 & 0.032 & 2.014 & 0.046 & 1.326 & 0.524 & -1.096 & 0.659 \\
\hline \multirow{8}{*}{ EPS operon (G2) } & $w z d$ & -2.924 & 0.015 & -2.667 & 0.072 & -2.370 & 0.036 & -2.358 & 0.100 & -2.016 & 0.000 \\
\hline & $w z m$ & 1.972 & 0.013 & 1.188 & 0.568 & 1.507 & 0.268 & -1.406 & 0.448 & -2.070 & 0.050 \\
\hline & $r m l A$ & 2.944 & 0.000 & -1.302 & 0.176 & 2.158 & 0.002 & 1.200 & 0.605 & 1.059 & 0.748 \\
\hline & $r m l D$ & 1.579 & 0.009 & 1.133 & 0.736 & 1.875 & 0.077 & 1.091 & 0.780 & -2.315 & 0.09 \\
\hline & $w z r$ & -1.010 & 0.764 & -1.088 & 0.807 & -1.739 & 0.757 & -2.252 & 0.115 & 1.130 & 0.582 \\
\hline & $w z b$ & 3.805 & 0.000 & -1.122 & 0.82 & 4.426 & 0.027 & 1.032 & 0.955 & 1.753 & 0.074 \\
\hline & welE & 7.056 & 0.000 & 1.645 & 0.31 & 4.341 & 0.001 & 2.960 & 0.069 & 2.327 & 0.011 \\
\hline & $n r p$ & -1.264 & 0.261 & -1.769 & 0.289 & 1.652 & 0.186 & 1.128 & 0.827 & 1.355 & 0.405 \\
\hline \multirow{8}{*}{$\begin{array}{l}\text { Amino acid biosynthesis } \\
\text { and lipid metabolism (G3) }\end{array}$} & cysK & 2.877 & 0.000 & -1.120 & 0.812 & 1.848 & 0.152 & -1.508 & 0.477 & -1.316 & 0.549 \\
\hline & R0011_04490 & 3.002 & 0.530 & 1.345 & 0.530 & 3.029 & 0.008 & -2.336 & 0.145 & 1.138 & 0.719 \\
\hline & metC & 1.275 & 0.278 & 1.539 & 0.251 & 1.948 & 0.038 & -3.984 & 0.005 & -1.761 & 0.000 \\
\hline & metA & 1.115 & 0.593 & 1.742 & 0.196 & 1.504 & 0.061 & -2.786 & 0.06 & -2.304 & 0.000 \\
\hline & $a m i$ & 1.629 & 0.051 & 1.506 & 0.005 & 4.288 & 0.191 & -1.873 & 0.191 & 1.105 & 0.833 \\
\hline & R0011_RS11250 & 1.479 & 0.177 & 1.556 & 0.143 & 3.485 & 0.020 & -2.545 & 0.093 & -4.348 & 0.009 \\
\hline & $\overline{c f a}$ & -1.120 & 0.770 & -1.027 & 0.967 & -1.724 & 0.066 & -4.098 & 0.009 & -1.721 & 0.113 \\
\hline & $f a b G$ & 1.432 & 0.177 & 1.426 & 0.316 & 2.057 & 0.066 & -1.282 & 0.622 & -1.211 & 0.360 \\
\hline \multirow{7}{*}{$\begin{array}{l}\text { Stress and cellular response } \\
\qquad(\mathrm{G} 4)\end{array}$} & $\operatorname{atpD}$ & 2.248 & 0.019 & 1.127 & 0.742 & 3.392 & 0.002 & -2.681 & 0.091 & -1.479 & 0.084 \\
\hline & dnaK & 1.761 & 0.062 & 1.194 & 0.619 & 1.237 & 0.502 & -1.770 & 0.329 & 1.174 & 0.519 \\
\hline & $\operatorname{luxS}$ & 3.145 & 0.003 & 1.418 & 0.471 & 1.097 & 0.755 & -2.439 & 0.168 & 1.325 & 0.492 \\
\hline & groES & 1.142 & 0.669 & -1.554 & 0.081 & -2.024 & 0.267 & 2.135 & 0.055 & -1.524 & 0.343 \\
\hline & AhpC & 3.233 & 0.008 & 1.631 & 0.153 & -1.391 & 0.703 & 3.667 & 0.004 & -1.035 & 0.872 \\
\hline & $\operatorname{atp} A$ & -1.623 & 0.066 & -3.378 & 0.005 & -1.433 & 0.484 & 1.510 & 0.433 & -2.625 & 0.022 \\
\hline & $\operatorname{clp} P$ & 1.458 & 0.363 & -1.908 & 0.177 & 2.594 & 0.000 & 1.420 & 0.554 & 1.273 & 0.623 \\
\hline \multirow{3}{*}{$\begin{array}{l}\text { Other functions (microbial } \\
\text { metabolism in diverse } \\
\text { environments) (G5) }\end{array}$} & rhaA & -1.259 & 0.528 & -1.33 & 0.304 & -1.789 & 0.412 & 2.241 & 0.188 & -2.525 & 0.039 \\
\hline & R0011_11803 & 1.616 & 0.223 & -2.849 & 0.000 & 1.222 & 0.737 & 1.706 & 0.149 & -3.049 & 0.006 \\
\hline & $p c a C$ & -1.1074 & 0.787 & -1.123 & 0.654 & -1.145 & 0.799 & 3.372 & 0.045 & -1.838 & 0.054 \\
\hline
\end{tabular}

a The control condition was monoculture fermentation with L. rhamnosus R0011. ${ }^{\mathrm{b}}$ Functions of the genes are described in Table S3. ${ }^{c}$ Relative expression ratios in bold are significantly different $(P<0.05)$. 
Table 2. Relative expression ratio (RER) of genes involved in the carbohydrate catabolism, EPS operon, amino acid biosynthesis and lipid metabolism, stress and cellular responses, and other functions (microbial metabolism in diverse environments) of L. rhamnosus ATCC 9595 over $24 \mathrm{~h}$ during growth in whey permeate in co-culture with $S$. cerevisiae.

\begin{tabular}{|c|c|c|c|c|c|c|c|c|c|c|c|}
\hline \multirow[b]{3}{*}{ Metabolic pathway } & \multirow[b]{3}{*}{ Gene $^{a}$} & \multicolumn{10}{|c|}{ Fermentation time } \\
\hline & & \multicolumn{2}{|c|}{$6 \mathrm{~h}$} & \multicolumn{2}{|c|}{$9 \mathrm{~h}$} & \multicolumn{2}{|c|}{$12 \mathrm{~h}$} & \multicolumn{2}{|c|}{$15 \mathrm{~h}$} & \multicolumn{2}{|c|}{$24 \mathrm{~h}$} \\
\hline & & RER $^{b}$ & $P^{\mathrm{c}}$ & $\mathrm{RER}^{\mathrm{b}}$ & $P^{\mathrm{c}}$ & $\mathrm{RER}^{\mathrm{b}}$ & $P^{\mathrm{c}}$ & RER $^{b}$ & $P^{\mathrm{c}}$ & RER $^{b}$ & $P^{\mathrm{c}}$ \\
\hline \multirow{9}{*}{$\begin{array}{l}\text { Carbohydrate catabolism } \\
\text { (G1) }\end{array}$} & galk & 1.037 & 0.846 & 1.233 & 0.547 & -1.456 & 0.884 & -2.083 & 0.036 & -2.564 & 0.004 \\
\hline & bgaC & -1.329 & 0.216 & 2.027 & 0.284 & 1.236 & 0.329 & 1.236 & 0.329 & 1.191 & 0.424 \\
\hline & gale & 1.341 & 0.312 & 1.114 & 0.801 & -1.531 & 0.459 & 1.097 & 0.692 & 1.656 & 0.076 \\
\hline & lact & 1.376 & 0.252 & 1.114 & 0.686 & -1.263 & 0.293 & -1.972 & 0.022 & -1.961 & 0.001 \\
\hline & galR. & 2.158 & 0.000 & 1.376 & 0.366 & -2.227 & 0.029 & -1.745 & 0.246 & -1.642 & 0.047 \\
\hline & lacD & -1.147 & 0.621 & 1.334 & 0.557 & 1.009 & 0.993 & 1.749 & 0.518 & -1.232 & 0.389 \\
\hline & $f b p$ & 1.373 & 0.275 & 1.425 & 0.282 & 2.674 & 0.021 & -2.571 & 0.001 & -2.801 & 0.000 \\
\hline & $a c k a$ & 1.265 & 0.451 & 1.696 & 0.125 & 1.491 & 0.014 & 1.100 & 0.735 & -1.127 & 0.624 \\
\hline & pyK & 3.517 & 0.000 & 3.115 & 0.014 & 2.271 & 0.024 & 2.460 & 0.000 & 1.376 & 0.196 \\
\hline \multirow{8}{*}{ EPS operon (G2) } & $w z d$ & 1.550 & 0.058 & 1.803 & 0.019 & -1.531 & 0.121 & 1.341 & 0.185 & 1.484 & 0.027 \\
\hline & $w z m$ & -1.001 & 0.997 & 1.546 & 0.075 & 1.403 & 0.321 & -1.145 & 0.132 & -1.397 & 0.502 \\
\hline & $r m l A$ & 1.406 & 0.364 & 1.307 & 0.446 & -1.088 & 0.856 & -1.086 & 0.642 & 1.037 & 0.882 \\
\hline & $r m l D$ & -1.007 & 0.982 & 1.448 & 0.353 & -1.029 & 0.000 & -4.505 & 0.001 & -3.413 & 0.000 \\
\hline & $w z r$ & 1.343 & 0.535 & 1.352 & 0.078 & -1.029 & 0.905 & -2.611 & 0.001 & -1.795 & 0.042 \\
\hline & $w z b$ & 1.452 & 0.029 & 1.054 & 0.876 & -2.075 & 0.293 & -3.745 & 0.003 & -1.267 & 0.478 \\
\hline & welE & 1.865 & 0.009 & 1.352 & 0.444 & -1.081 & 0.709 & -3.390 & 0.024 & -1.152 & 0.611 \\
\hline & $n r p$ & 2.416 & 0.001 & 1.568 & 0.312 & -1.027 & 0.886 & -3.937 & 0.002 & -1.089 & 0.706 \\
\hline \multirow{8}{*}{$\begin{array}{l}\text { Amino acid transport and } \\
\text { lipid metabolism (G3) }\end{array}$} & cysK & 1.029 & 0.93 & 1.470 & 0.178 & -1.114 & 0.641 & 1.006 & 0.987 & -2.075 & 0.000 \\
\hline & R0011_04490 & -1.290 & 0.618 & -1.143 & 0.582 & 4.329 & 0.033 & -3.215 & 0.062 & -11.494 & 0.007 \\
\hline & metC & -1.151 & 0.704 & -1.385 & 0.104 & -1.385 & 0.041 & 3.066 & 0.191 & -21.739 & 0.001 \\
\hline & $\operatorname{met} A$ & -2.227 & 0.077 & -1.533 & 0.315 & 2.81 & 0.077 & -1.337 & 0.639 & -9.524 & 0.003 \\
\hline & ami & -1.018 & 0.955 & 1.103 & 0.709 & 4.496 & 0.021 & -1.898 & 0.241 & -14.286 & 0.006 \\
\hline & R0011_RS11250 & 1.335 & 0.493 & -1.326 & 0.332 & 3.671 & 0.04 & -2.387 & 0.076 & -10.101 & 0.009 \\
\hline & $c f a$ & 2.528 & 0.074 & -1.472 & 0.291 & 5.175 & 0.021 & -2.070 & 0.136 & -15.873 & 0.007 \\
\hline & $f a b G$ & -1.661 & 0.502 & -2.898 & 0.025 & 1.668 & 0.54 & 1.627 & 0.447 & -1.222 & 0.728 \\
\hline \multirow{7}{*}{$\begin{array}{l}\text { Stress and cellular responses } \\
\text { (G4) }\end{array}$} & $\operatorname{atpD}$ & 1.654 & 0.219 & 2.064 & 0.168 & 5.172 & 0.001 & -3.731 & 0.065 & -7.692 & 0.043 \\
\hline & dnaK & -1.199 & 0.457 & -1.111 & 0.802 & 3.01 & 0.017 & -2.114 & 0.249 & -6.452 & 0.046 \\
\hline & $\operatorname{luxS}$ & -1.003 & 0.998 & -2.481 & 0.000 & 3.736 & 0.033 & -2.985 & 0.091 & -4.525 & 0.12 \\
\hline & groES & -1.420 & 0.138 & -1.092 & 0.837 & 3.375 & 0.011 & -2.941 & 0.127 & -8.333 & 0.041 \\
\hline & ahpC & 1.15 & 0.729 & 1.149 & 0.496 & 3.748 & 0.027 & -3.333 & 0.077 & -5.435 & 0.112 \\
\hline & $\operatorname{atp} A$ & 1.316 & 0.609 & 1.704 & 0.042 & 17.286 & 0.004 & -3.745 & 0.03 & -3.817 & 0.191 \\
\hline & $\operatorname{clp} P$ & 1.151 & 0.7 & 1.821 & 0.035 & 8.082 & 0.006 & -4.065 & 0.009 & -3.236 & 0.170 \\
\hline \multirow{3}{*}{$\begin{array}{l}\text { Other functions (microbial } \\
\text { metabolism in diverse } \\
\text { environments) (G5) }\end{array}$} & rhaA & -1.314 & 0.492 & 1.044 & 0.875 & 4.455 & 0.052 & -4.237 & 0.002 & -3.731 & 0.014 \\
\hline & R0011_11803 & 1.382 & 0.380 & 1.365 & 0.241 & 3.482 & 0.036 & -3.135 & 0.022 & -3.597 & 0.034 \\
\hline & pcaC & 1.870 & 0.014 & 1.599 & 0.119 & 6.366 & 0.021 & -3.831 & 0.029 & -3.759 & 0.107 \\
\hline
\end{tabular}

${ }^{a}$ The control condition was monoculture fermentation with L.rhamnosus ATCC 9595. ${ }^{\mathrm{b}}$ Functions of the genes are described in Table S3. ${ }^{c}$ Relative expression ratios in bold are significantly different $(P<0.05)$.

Table 3. Relative expression ratio (RER) of genes involved in the carbohydrate catabolism, EPS operon, amino acid biosynthesis and lipid metabolism, stress and cellular responses, and other functions (microbial metabolism in diverse environments) of L. rhamnosus RW-9595M over $24 \mathrm{~h}$ during growth in whey permeate in co-culture with $S$. cerevisiae.

\begin{tabular}{|c|c|c|c|c|c|c|c|c|c|c|c|}
\hline \multirow[b]{3}{*}{ Metabolic pathway } & \multirow[b]{3}{*}{ Gene $^{a}$} & \multicolumn{10}{|c|}{$\begin{array}{l}\text { Fermentation } \\
\text { Time }\end{array}$} \\
\hline & & \multicolumn{2}{|c|}{$6 \mathrm{~h}$} & \multicolumn{2}{|c|}{$9 \mathrm{~h}$} & \multicolumn{2}{|c|}{$12 \mathrm{~h}$} & \multicolumn{2}{|c|}{$15 \mathrm{~h}$} & \multicolumn{2}{|c|}{$24 \mathrm{~h}$} \\
\hline & & $\mathrm{RER}^{\mathrm{b}}$ & $P^{\mathrm{c}}$ & RER $^{b}$ & $P^{\mathrm{c}}$ & RER $^{b}$ & $P^{\mathrm{c}}$ & $\mathrm{RER}^{\mathrm{b}}$ & $P^{\mathrm{c}}$ & RER $^{b}$ & $P^{\mathrm{c}}$ \\
\hline \multirow{8}{*}{$\begin{array}{l}\text { Carbohydrate catabolism } \\
\text { (G1) }\end{array}$} & galk & 2.608 & 0.045 & 5.260 & 0.001 & 7.953 & 0.001 & -1.014 & 0.978 & -1.135 & 0.539 \\
\hline & bgaC & 10.247 & 0.007 & 7.990 & 0.000 & 5.455 & 0.254 & 1.435 & 0.584 & 1.329 & 0.331 \\
\hline & gale & 3.566 & 0.005 & 6.991 & 0.002 & 1.114 & 0.001 & -7.813 & 0.838 & -1.282 & 0.305 \\
\hline & lact & 3.795 & 0.049 & 5.012 & 0.002 & 3.565 & 0.012 & 2.975 & 0.159 & 1.095 & 0.706 \\
\hline & galR & 2.309 & 0.135 & 6.943 & 0.001 & 7.781 & 0.005 & 2.104 & 0.311 & 1.906 & 0.134 \\
\hline & lacD & 4.132 & 0.002 & 5.749 & 0.000 & 8.371 & 0.000 & 7.336 & 0.021 & -1.107 & 0.468 \\
\hline & $f b p$ & 2.981 & 0.079 & 8.925 & 0.002 & 2.218 & 0.057 & 3.090 & 0.138 & 1.700 & 0.100 \\
\hline & acka & 6.412 & 0.012 & 5.675 & 0.001 & 4.580 & 0.006 & 1.325 & 0.725 & -1.005 & 0.992 \\
\hline
\end{tabular}


Table 3. Cont.

\begin{tabular}{|c|c|c|c|c|c|c|c|c|c|c|c|}
\hline & \multirow[b]{3}{*}{$w z d$} & \multicolumn{10}{|c|}{$\begin{array}{l}\text { Fermentation } \\
\text { Time }\end{array}$} \\
\hline & & \multicolumn{2}{|c|}{$6 \mathrm{~h}$} & \multicolumn{2}{|c|}{$9 \mathrm{~h}$} & \multicolumn{2}{|c|}{$12 \mathrm{~h}$} & \multicolumn{2}{|c|}{$15 \mathrm{~h}$} & \multicolumn{2}{|c|}{$24 \mathrm{~h}$} \\
\hline \multirow{8}{*}{ EPS operon (G2) } & & 5.979 & 0.017 & 4.152 & 0.026 & 4.635 & 0.000 & -1.418 & 0.555 & 1.299 & 0.39 \\
\hline & $w z m$ & 8.063 & 0.003 & 5.085 & 0.008 & 10.758 & 0.000 & -1.146 & 0.644 & 1.020 & 0.899 \\
\hline & rmlA & 4.071 & 0.004 & 5.303 & 0.005 & 7.322 & 0.001 & 1.169 & 0.783 & 1.094 & 0.680 \\
\hline & $r m l D$ & 1.602 & 0.574 & 2.946 & 0.213 & 1.924 & 0.369 & 1.581 & 0.53 & -1.595 & 0.001 \\
\hline & $w z r$ & 3.774 & 0.06 & 3.859 & 0.002 & 2.722 & 0.052 & 2.268 & 0.331 & -1.300 & 0.198 \\
\hline & $w z b$ & 3.611 & 0.032 & 5.701 & 0.001 & 4.635 & 0.012 & 2.415 & 0.249 & 1.020 & 0.936 \\
\hline & welE & 1.855 & 0.251 & 2.326 & 0.01 & 2.832 & 0.034 & 2.598 & 0.206 & 1.047 & 0.823 \\
\hline & $n r p$ & 3.293 & 0.067 & 2.951 & 0.001 & 3.926 & 0.009 & 11.522 & 0.003 & 1.868 & 0.054 \\
\hline Metabolic pathway & Gene $^{a}$ & RER $^{b}$ & $P^{\mathrm{c}}$ & RER $^{\mathrm{b}}$ & $P^{\mathrm{c}}$ & $\mathrm{RER}^{\mathrm{b}}$ & $P^{\mathrm{c}}$ & RER $^{b}$ & $P^{\mathrm{c}}$ & $\mathrm{RER}^{\mathrm{b}}$ & $P^{\mathrm{c}}$ \\
\hline \multirow{8}{*}{$\begin{array}{l}\text { Amino acid transport and } \\
\text { lipid metabolism (G3) }\end{array}$} & cysK & 1.954 & 0.302 & 5.126 & 0.002 & 4.479 & 0.003 & 3.955 & 0.068 & 1.046 & 0.969 \\
\hline & R0011_04490 & 2.318 & 0.292 & 4.538 & 0.000 & -7.519 & 0.003 & 2.918 & 0.188 & -4.854 & 0.004 \\
\hline & metC & 2.600 & 0.128 & 3.746 & 0.001 & -5.319 & 0.137 & 2.979 & 0.323 & -9.091 & 0.000 \\
\hline & met $A$ & 1.342 & 0.738 & 3.384 & 0.003 & -4.878 & 0.002 & 7.028 & 0.053 & -4.016 & 0.012 \\
\hline & ami & 2.938 & 0.090 & 5.721 & 0.001 & -7.812 & 0.000 & 4.948 & 0.038 & -6.098 & 0.001 \\
\hline & R0011_RS1250 & 3.994 & 0.027 & 3.913 & 0.005 & -6.369 & 0.000 & 3.936 & 0.051 & -4.274 & 0.009 \\
\hline & $\overline{c f a}$ & 7.561 & 0.005 & 3.523 & 0.026 & -9.009 & 0.000 & 4.535 & 0.016 & -6.711 & 0.005 \\
\hline & $f a b G$ & 1.800 & 0.225 & 1.790 & 0.367 & -2.898 & 0.000 & 15.284 & 0.004 & 1.934 & 0.295 \\
\hline \multirow{7}{*}{$\begin{array}{l}\text { Stress and cellular responses } \\
\qquad(\mathrm{G} 4)\end{array}$} & $\operatorname{atpD}$ & 5.033 & 0.009 & 11.191 & 0.001 & -9.345 & 0.000 & 2.502 & 0.203 & -3.460 & 0.002 \\
\hline & dnaK & 2.495 & 0.025 & 4.668 & 0.014 & -5.236 & 0.024 & 4.440 & 0.042 & -2.732 & 0.006 \\
\hline & $\operatorname{luxS}$ & 2.982 & 0.121 & 2.091 & 0.06 & -6.493 & 0.000 & 3.145 & 0.119 & -1.916 & 0.053 \\
\hline & groES & 2.105 & 0.08 & 4.750 & 0.009 & -5.848 & 0.001 & 3.198 & 0.157 & -3.509 & 0.007 \\
\hline & $A h p C$ & 3.441 & 0.041 & 5.961 & 0.006 & -6.493 & 0.041 & 2.817 & 0.180 & -2.294 & 0.02 \\
\hline & $\operatorname{atp} A$ & 3.937 & 0.014 & 8.836 & 0.002 & -30.30 & 0.009 & 2.512 & 0.131 & -1.610 & 0.135 \\
\hline & $\operatorname{clp} P$ & 3.444 & 0.009 & 9.448 & 0.000 & -14.08 & 0.009 & 2.308 & 0.178 & -1.368 & 0.499 \\
\hline \multirow{3}{*}{$\begin{array}{l}\text { Other functions (microbial } \\
\text { metabolism in diverse } \\
\text { environments) (G5) }\end{array}$} & rhaA & 2.281 & 0.009 & 5.391 & 0.017 & -7.692 & 0.004 & 2.225 & 0.173 & -1.565 & 0.251 \\
\hline & R0011_11803 & 4.135 & 0.032 & 7.082 & 0.000 & -6.061 & 0.004 & 2.992 & 0.046 & -1.520 & 0.25 \\
\hline & pcaC & 5.594 & 0.002 & 8.294 & 0.003 & -10.98 & 0.002 & 2.449 & 0.173 & -1.592 & 0.063 \\
\hline
\end{tabular}

${ }^{\mathrm{a}}$ Functions of the genes are described in Table S3. ${ }^{\mathrm{b}}$ The control condition was monoculture fermentation with $L$. rhamnosus RW-9595 $\mathrm{M}^{\mathrm{c}}$ Relative expression ratios in bold are significantly different $(P<0.05)$.
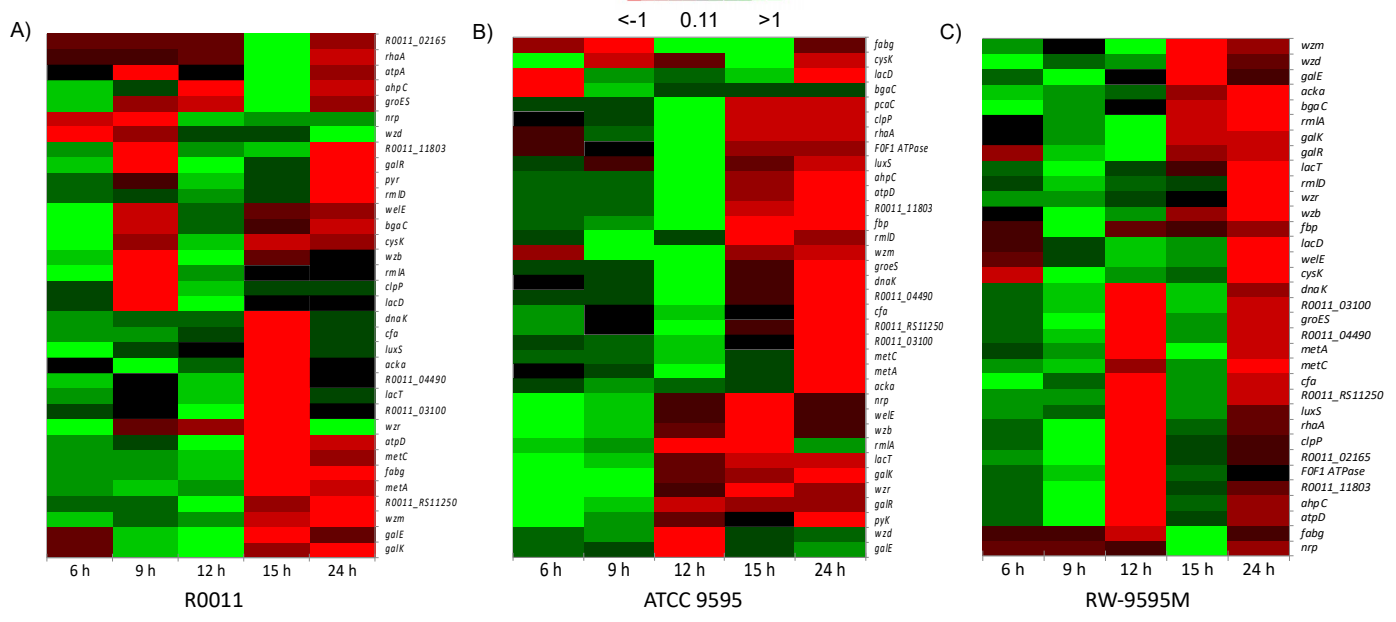

Figure 4. Heat map representation of the ratio of relative gene expression involved in carbohydrate catabolism, EPS operons, amino acid biosynthesis, lipid metabolism (cellular membrane, stress and cellular response) and other functions (microbial metabolism in diverse environments) over fermentation time (6, 9, 12, 15, 24 h) for L. rhamnosus strains R0011 (A); ATCC 9595 (B) and RW-9595M (C). Red shows under-expression while green denotes over-expression relative to the control condition (monoculture fermentation).

(i) Group 1: Carbohydrate catabolism (G1)

Co-culture significantly influenced $(\mathrm{p}<0.05)$ sugar metabolism for the three strains. A clear over-expression of genes was observed during the first $12 \mathrm{~h}$ of fermentation. L. rhamnosus R0011 in co-culture had $62.5 \%$ of target genes over-expressed between 6 and $12 \mathrm{~h}(\mathrm{bgaC}, \operatorname{lacT}$, galR, lacD, ackA, 
and $p y K)$. The largest change in gene expression was found for the $b g a C$ gene $(\mathrm{RER}=7.754, P<0.001)$ after $6 \mathrm{~h}$ of co-culture. For L. rhamnosus ATCC 9595, the percentage of over-expressed genes was limited to $50 \%$ ( $g a l R$, ack $A$, fbp , and $p y K$ ) between six and $12 \mathrm{~h}$, while genes lacT, fbp galK, and galR were under-expressed between 15 and $24 \mathrm{~h}$. Pyruvate kinase (pyk) was over-expressed (RER of 3.517, $P=0.000)$ during $80 \%$ of experience duration $(6,12,15$, and $24 \mathrm{~h})$. In contrast, L. rhamnosus RW-9595M showed an over-expression of $75 \%$ of target genes for this group $(g a l K$, bgaC, galE, lacT, galR, lacD, $f b p$ and $a c k A)$ at 6, 9, and $12 \mathrm{~h}$ of fermentation. Tagatose 1,6-diphosphate aldolase gene $(l a c D)$ was over-expressed for $80 \%$ of the samples $(6,9,12,15$ and $24 \mathrm{~h})$ in co-culture compared with monoculture. The largest change in gene expression was found for the $b g a C$ gene $(\mathrm{RER}=10.247, P=0.007)$ after $6 \mathrm{~h}$ of fermentation.

\section{(ii) Group 2: EPS operons (G2)}

In all strains, exopolysaccharide biosynthesis was influenced by yeast presence. L. rhamnosus R0011 showed over-expression of genes $w z m, r m l A, r m l D, w z b$ and welE after 6 and $12 \mathrm{~h}$ (RER between 1.972 and $7.056 P<0.05)$. However, gene $w z d$ was under-expressed in co-culture during $60 \%$ of the fermentation time when compared to monoculture. L. rhamnosus ATCC 9595 exhibited an over-expression of genes $w z b$, welE, and $n r p$ after $6 \mathrm{~h}$ (RER 1.452, 1.865 and $2.416 P<0.05$, respectively) and $w z d$ after 9 and $24 \mathrm{~h}$ (RER 1.803 and $1.484 P<0.05$, respectively). After 15 hours, wzr, $w z b$, welE, and $n r p$ were under-expressed. The $r m l D$ gene was under-expressed during $60 \%$ of the fermentation time. Strain RW-9595M showed more than $60 \%$ of targeted genes for the EPS operon $(w z d, w z m, r m l A$, $w z r, w z b$, welE, and $n r p$ ) were over-expressed after 6, 9, and $12 \mathrm{~h}$ (RER ranging between 2.951 and $11.522 P<0.05)$. After 24 hours, the $r m l D$ gene was significantly under-expressed in co-culture (RER $-1.595 P=0.001)$.

(iii) Group 3: Amino acid biosynthesis and lipid metabolism (G3)

In all tested strains, amino acid biosynthesis and lipid metabolism were influenced significantly by the presence of $S$. cerevisiae. For the R0011 strain, the over-expressed genes were: $c y s K$, fabG, ami, R0011_RS11250, and metC (RER ranging between 1.504 and $3.485 P<0.05$ ) after 6 and $12 \mathrm{~h}$. After 15 hours, genes coding for metC, metA, R0011_RS11250 and cfa were under-expressed in co-culture (RER ranging between -1.761 and $-3.984 P<0.01$ ). L. rhamnosus ATCC 9595 had $50 \%$ of target genes (R0011_RS4490, ami, R0011_RS11250, and cfa) over-expressed after $15 \mathrm{~h}$ (RER ranging between 3.671 and $5.175 P<0.05)$. In contrast, after $24 \mathrm{~h}$, most target genes $(>80 \%)$ were under-expressed in relation to monoculture (RER ranging between -2.075 and $-21.739 P<0.01$ ). L. rhamnosus RW-9595M showed two trends: a strong over-expression after 9 hours for 80\% of targeted genes (cysK, R0011_RS4490, ami, R0011_RS11250, metC, metA, and cfa); for two genes (R0011_RS11250 and $c f a)$ after $6 \mathrm{~h}$ and finally for genes met $A$ and $c f a$ after $15 \mathrm{~h}$ (RER values ranging between 1.790 and $5.721 P<0.05$ ). Meanwhile, after 12 and $24 \mathrm{~h}, 75 \%$ of target genes (R0011_RS4490, ami, R0011_RS11250, metC, metA, cfa, and fabG, $P<0.005)$ were under-expressed.

(iv) Group 4: Stress and cellular response (G4)

For strain R0011, the overexpressed genes at 6, 12, and $15 \mathrm{~h}$ were $\operatorname{luxS}$, atpD, ahpC, and $\operatorname{clpP}$ (RER range, 2.248 to 3.392, $P<0.05$ ). The gene coding for atp $A$ was repressed at 9 and $24 \mathrm{~h}$ in co-culture (Table 1). For strain ATCC 9595, all target genes involved with stress and cellular responses were over-expressed after $12 \mathrm{~h}$ of co-culture compared to monoculture (RER range, +3.01 to +17.29 , $P<0.05)$. However, at the end of the process $(15-24 \mathrm{~h})$, genes atp $A, \operatorname{clpP}, \operatorname{atp} D, d n a K$, and groES were under-expressed in co-culture (Table 2). RW9595-M showed that a higher percentage $(75 \%-100 \%)$ of the targeted genes were over-expressed ( $\operatorname{atpD}, \operatorname{dnaK}, \operatorname{luxS}$, groES, ahpC, atpA, and $\operatorname{clp} P$ ) after 6 and $9 \mathrm{~h}$ of co-culture (RER values ranging between 2.091 and $11.191 P<0.05$ ). In contrast, all the genes were under-expressed principally at $12 \mathrm{~h}$ (RER range, -2.73 to $-30.3 P<0.05$ ) (Table 3 ). 
(v) Group 5: Other functions (microbial metabolism in diverse environments) (G5)

After $15 \mathrm{~h}$, the L. rhamnosus R0011 strain showed over-expression of the gene coding for carboxymuconolactone decarboxylase $p c a C(\mathrm{RER}=3.372, P=0.045$, Table 1$)$. In contrast, the other two genes, the xylanase coding gene R0011_11803 and the rhamnose isomerase, rhaA, were under-expressed in co-culture after $24 \mathrm{~h}$. For ATCC 9595, the genes pcaC and R0011_11803011 were over-expressed between 6 and $12 \mathrm{~h}$, but after $15 \mathrm{~h}$, all three genes were under-expressed in co-culture (Table 2). L. rhamnosus RW-9595M revealed an over-expression of three genes between 6 and $9 \mathrm{~h}$. The gene coding for xylanase, R0011_11083 was also over-expressed after $15 \mathrm{~h}$. However, after $12 \mathrm{~h}$, all these same genes were under-expressed in co-culture.

\subsection{Gene Co-Expression Networks}

A co-expression network is evident from significant $(p<0.05)$ and strong $(p<0.01)$ correlations between gene pairs. For each strain, the best network (Figure 5A-C) only shows nodes (genes) with strong $(\mathrm{r}>0.8)$ correlations and high significance $(P<0.05$ or $P<0.01)$. For L. rhamnosus R0011, the network is composed of the co-expression of 23 genes belonging to a number of functional groups (Fig. 6A). The genes (nodes) forming the network are interconnected by the gene coding for dipeptidyl aminopeptidase (R0011_04490) with BC $=0.49$ and degree $=6$. In the central part of the network, genes linked to groups G3 and G4 are surrounded by genes belonging to G1 and G2 groups. Most are positively correlated, but groES is negatively correlated with galE and ackA. Gene cysK was expressed together with genes of the G2 group and at the same time with the gene (R0011_04490). A complementary network indicated that the expression of rhamnose isomerase (rhaA) and carboxymuconolactone decarboxylase $(p c a C)$ are strongly correlated.

For L. rhamnosus ATCC 9595, the relationship between the target genes formed more than one significant network (Figure 5B). A bigger network composed of 16 genes from groups G3, G4 and G5 all linked to the wzm gene (G2), which is also connected to G1 genes such as ackA. Gene $\operatorname{ahpC}(\mathrm{BC}=0.345$ and degree $=10$ ) seems to be an important node between two sub-networks. The other smaller networks show EPS operon genes (G2) principally associated with G1-type genes. An interaction between genes coding wzd (G2) and cysK (G3) was also observed.

For L. rhamnosus strain RW-9595M, two distinct networks were obtained (Figure 5C). The first of these, formed by 14 genes from groups G1 and G2, represent the co-expression of gene cysK (G3) with lacD (G1) or G2-type genes such as welE and rmlD. Genes coding for ackA $(\mathrm{BC}=0.54$ and degree $=5)$, $w z b(\mathrm{BC}=0.54$ and degree $=4)$ and $\operatorname{rmlD}(\mathrm{BC}=0.38$ and degree $=4)$ connect the parts of the network and are important genes because of their centrality. The second network represents the correlation between 16 genes, all belonging to groups G3, G4 and G5. In this network, as was also observed for L. rhamnosus strain ATCC 9595, the gene coding for $\operatorname{ahpC}(\mathrm{BC}=0.297$ and degree $=11)$ appeared as a node with high connectivity. Genes met $C$ and met $A$ are correlated with genes linked to cell membrane composition. The analysis of the networks (Figure 5) displays the common co-expression of genes such as $w z b$-lacT, rmlA with galR, and/or with $b g a C$ for the three strains of L. rhamnosus. 
1)

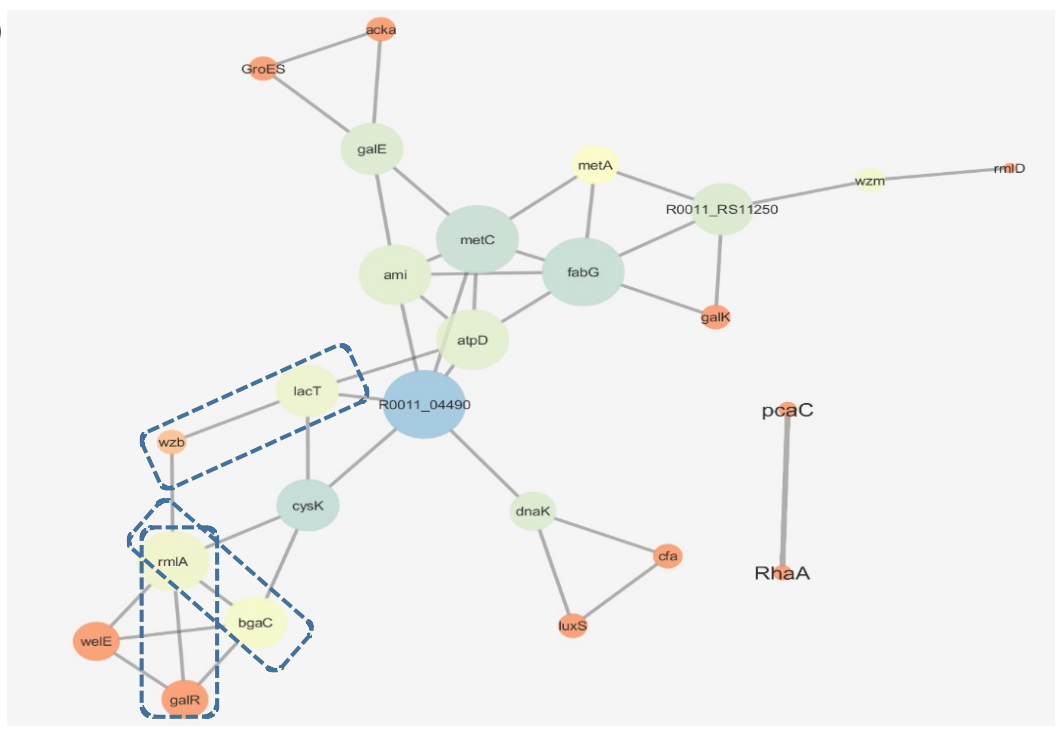

2)

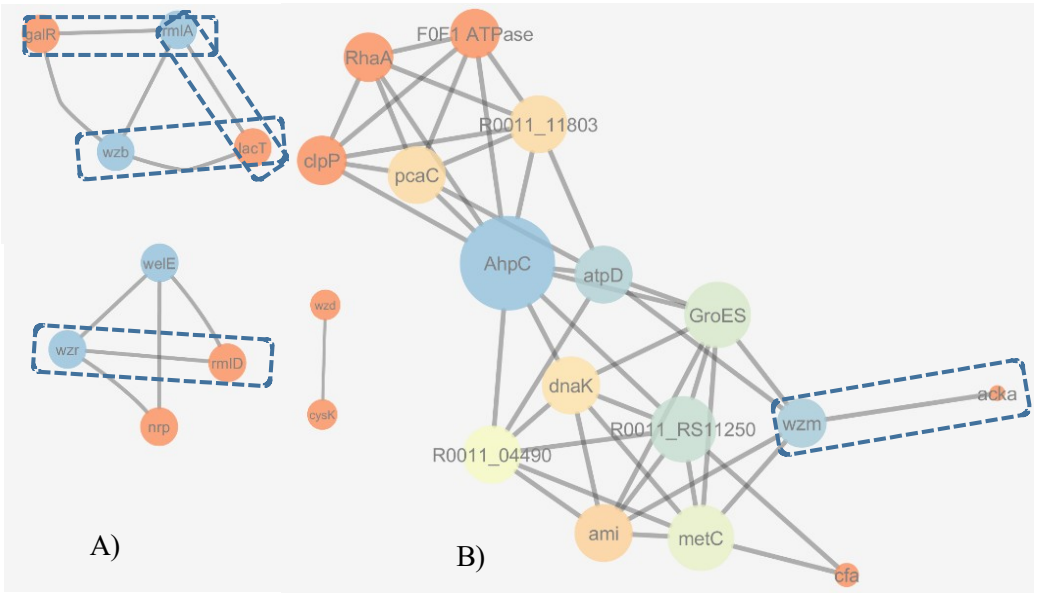

3)

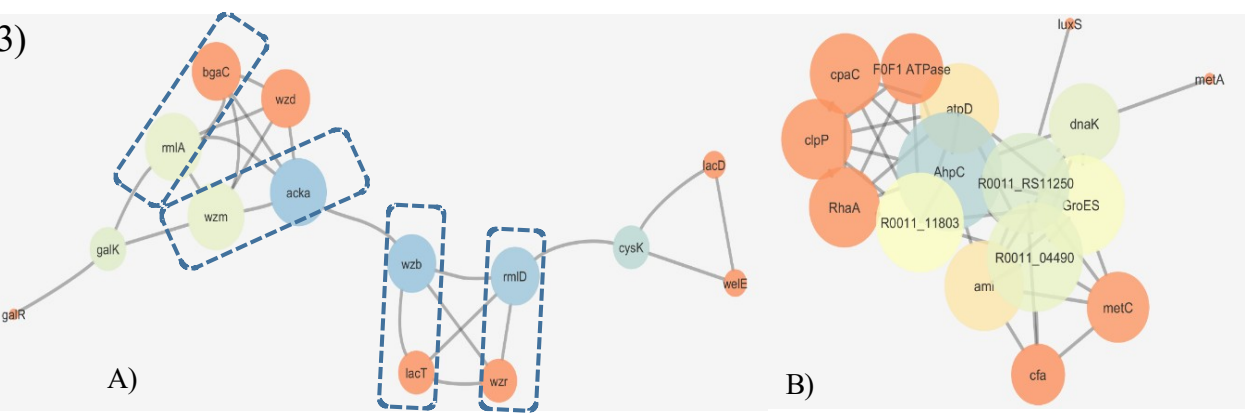

Figure 5. Co-expression gene network of L. rhamnosus strains R0011 (1); ATCC 9595 (2) and RW-9595M (3) obtained using Cytoscape 3.4. The illustrated genes had a significant $(P<0.05)$ strong correlation (correlation index $>0.8$ ). The largest nodes (circle size) are those with the high level of degree. In the above figure, the blue nodes had higher values of Betweenness Centrality (BC) and the orange nodes had lower BC values. Non-continuous traits show a co-expression pattern found for the three strains of L. rhamnosus R0011, ATCC $9595 \mathrm{M}$, and RW-9595M.

\section{Discussion}

This study demonstrates that co-culture with the yeast $S$. cerevisiae was effective in enhancing the exopolysaccharide production of three strains of L. rhamnosus R0011, ATCC 9595, and RW-9595M in cultures without $\mathrm{pH}$ control. This is a very important aspect because the absence of $\mathrm{pH}$ control 
could allow the simplification and reduction of cost of the fermentation process coupled to a better EPS production in co-culture.

Our results clearly showed that $48 \mathrm{~h}$ of co-culture did not show any impact on the growth or viability of strains measured by viable cultivable counts in $\mathrm{CFU} / \mathrm{mL}$, total counts by qPCR and by PMA-qPCR. A previous study found that co-culture improved the viability of L. rhamnosus HN001 in fermented milk after 1 week of storage at $30^{\circ} \mathrm{C}$ [39]. Further experiments are required in order to evaluate the effect of time of co-culture and storage on viability of the strains in co-culture.

Similarities between the three strains were detected during fermentation. The co-culture did not affect lactose consumption or lactic acid production for RW-9595M or R0011. On the contrary, co-culture had an effect on L. rhamnosus ATCC 9595 with relation to lactose consumption. These differences showed that the interactions between bacteria and yeast are strain-dependent.

Relative gene expression depended on the growth phase for all studied strains. In co-culture, the three strains of L. rhamnosus show simultaneous transcription of two pathways to metabolize lactose from whey; through the tagatose-6-phosphate and the Leloir pathway. Tsai and $\mathrm{Li}$ (2006) [40] reported that these two pathways depend on the activation of the lacTEGF operon by the inducing gene lacT. Lactose can be hydrolyzed by the activation of beta-galactosidase ( $b g a C$ ) to obtain glucose and galactose. Galactose could then be metabolized by the Leloir pathway by the activation of the galKETRM operon. During fermentation, bacterial cells were in an acid medium $(\mathrm{pH}<4)$, with the presence of lactate issuing from the catabolism of sugars to obtain energy. Linked to lactic acid production, strains showed over-expression of genes coding for pyruvate kinase ( $p y K)$ and fructose 1,6 biphosphatase $(f b p)$ during co-culture.

During the stationary phase, the gene coding for acetate kinase (ackA) was over-expressed for all three strains. The presence of acetic acid in media was detected and indicated the induction of the mixed acid metabolic pathway for Lactobacillus strains. In co-culture, acetic acid concentration in the culture media was similar (L. rhamnosus R0011) or inferior (L. rhamnosus RW-9595M and ATCC 9595) to monoculture. In this sense, Shang et al. [41] reported that $S$. cerevisiae can remove acetic acid and is used to eliminate excessive amounts of it as a practical approach during alcoholic fermentation.

For the L. rhamnosus RW-9595M strain, producing the highest amount of EPS, gene ackA seems to be an important node for the co-expression network, as gene $w z b$ for the EPS operon (G2). Gene ackA interacts with genes coding for G2 group EPS operon enzymes ( $w z d, w z b, w z m$ and $r m l A)$ and one of G1 group sugar metabolism ( $b g a C)$. For ATCC 9595, gene ackA showed co-expression only with gene wzm. For R0011, gene ackA had a positive co-expression with gene galE, however it had negative correlation with groES. Acetate belongs to the metabolic pathway used for lactate degradation in mixed acid metabolism. The amount of acetate kinase (ackA) increased during growth on cheese broth without $\mathrm{pH}$ control [42]. There is some evidence that Lactobacilli modify the pyruvate metabolism and increase the synthesis of basic compounds (e.g., lysine, diacetyl/acetoin), energy-rich intermediates (such as ATP and NADH), exopolysaccharides, and/or glycogen at the expense of lactic acid [43]. According to the literature, L. rhamnosus strains can utilize pyruvate as a growth substrate during cheese ripening, in this way they are able to increase the amount of pyruvate oxidase (POX) or phosphotransacetylase for synthesizing acetate [44]. Additional ATP generated by acetate kinase is an alternative carbon source for Lactobacillus that permits an increment of biomass production [45,46].

Throughout fermentation, the phenolic acid profile of corn steep liquor used as nitrogen source in the culture medium was modified with an increase of caffeic and protocatechuic acid and a reduction of ferulic acid concentration in the medium. At the same time, the bioconversion of phenolic acids showed the over-expression of $p c a C$ genes involved in the conversion of protocatechuate to 3-oxoadipate. Over-expression of gene rhaA was observed for L. rhamnosus strains in co-culture with baker's yeast. Network analysis of L. rhamnosus strains revealed co-expression of ( rhaA) with carboxymuconolactone ( pcaC) and/or xylanase (R0011_11803). Recently, studies have shown that lactic acid bacteria can use phenolic acids as external electron acceptors to gain additional metabolic energy to counteract the stressful conditions generated by phenolics $[47,48]$. On the other hand, the utilization of corn steep 
liquor in the culture medium leads to bioactive substances with potential health benefits for humans through bacterial metabolism of phenolic acids [48].

The PCA indicates that EPS production was principally associated with growth and lactic acid production for $L$. rhamnosus strains, as previously shown $[4,10]$. The stimulation of kefiran production and the growth of L. kefiranofaciens JCM 6985 by yeast began in the early exponential growth phase [20]. Previous reports indicated that the largest EPS production of L. rhamnosus RW-9595M (about 85\% of the maximum EPS concentration) occurred during the growth phase with a concentration of $2.3 \mathrm{~g} / \mathrm{L}$ in immobilized conditions and under $\mathrm{pH}$ control [13]. In this study, the EPS production increased in co-culture relative to monoculture for the three strains. It was demonstrated that co-culture of L. paracasei with S. cerevisiae resulted in over-expression of a gene coding for polyprenyl glycosylphosphotransferase linked to EPS production [49]. The same authors suggested that EPS production could be induced by direct contact of bacteria and yeast through recognition of mannan in the yeast cell wall and that adhesion of LAB cells to yeast cells triggers EPS production in the LAB cells because the adhesion leads to more efficient consumption of lactic acid by the yeast cells.

Despite the positive effect of co-culture, the quantity of EPS produced was different for each strain. The most productive strain was L. rhamnosus RW-9595M with $1.35 \mathrm{~g} / \mathrm{l}$ in co-culture without $\mathrm{pH}$ control in this study, corresponding to a production five times greater than the other strains. Transcriptome analysis of the three strains indicates that after $6 \mathrm{~h}$ (exponential phase) of co-culture, each strain over-expressed the gene responsible for EPS polymerization: phosphatase $(w z b)$. However, for $L$. rhamnosus RW-9595M, this gene is over-expressed and the network analysis of co-expression indicated it as an important node in target gene interactions. Network analysis also revealed a common behavior among all three strains with the co-expression of $w z b$ (G2) and lacT (G1). The $w z b$ protein is involved in chain length determination and LacT acts as an anti-terminator protein of the galKETRM operon. The co-expression of genes coding for $r m l A$ (G2) with galR and/or bgaC (G1) represent a complementary aspect of network analysis. In the EPS operon, $r m l A$ and $w z b$ are co-expressed for R0011 and ATCC 9595 and $r m l D$ and $w z r$ are co-expressed for ATCC 9595 and RW-9595M. The expression of $r m l A-D$ genes was activated independently of EPS biosynthesis to form the cell wall polysaccharides, but co-transcription of these genes with the EPS biosynthesis gene cluster might increase the dTDP-L-rhamnose pool available for biosynthesis of EPS [10]. The levels of EPS production and even the repeating unit sugar composition of EPS could be influenced by using a conditional $r f b B D(r m l B D)$ mutant of L. lactis [50].

Other potential targets for acid stress exist, such as the cell wall and cytoplasmic membrane. In co-culture, an over-expression of the gene coding for enzyme cyclopropane-fatty-acyl-phospholipid synthase $(c f a)$ or the gene encoding the enzyme regulating non-saturated fat acids elongation $(f a b G)$ for L. rhamnosus RW-9595M and L. rhamnosus ATCC 9595 was observed. Acetyltransferase (R0011_RS11250) coding for membrane fatty acid biosynthesis was over-expressed for the three strains. Cyclopropanation increases membrane stability when facing stress conditions affecting the membrane, such as acid stress [51]. The same strategy to resist stress conditions was described for Lactobacillus plantarum at $\mathrm{pH} 3$ [52].

From Group 3, the overexpression of the gene coding for cysteine synthase (cysK) which participates in cysteine and methionine biosynthesis was observed for L. rhamnosus R0011 and L. rhamnosus RW-9595M. This gene is coded by the metA-cysK operon and permits cysteine production from serine. These genes form the cysteine-cystathionine cycle, allowing $\mathrm{NH}_{3}$ production and stimulating lactic and acetic acid synthesis by the pyruvate pathway.

Genes linked to $\mathrm{pH}$ homeostasis regulation such as the proton pump F0F1-ATPase, expression of general proteins associated with stress and the chaperone proteins that repair damaged DNA were monitored during fermentation (G4). Genes coding for F0F1 ATP synthase (atpD or atpA), proteins responsible for maintaining the proton gradient throughout the cell membrane, were over-expressed in all three strains. In the same manner, L. plantarum under acid stress showed increased expression of the atp $A$ gene, which was proposed to increase acid tolerance [53]. 
The gene coding for alkyl hydroperoxyde reductase $(a h p C)$, a catalyzer for the reduction of organic hydroxide to protect cells, was over-expressed by the three strains. Genes dnaK, groES and clpP were over-expressed in L. rhamnosus RW-9595M and ATCC 9595. Transcriptomic and proteomic studies highlighted that $d n a K$ and groESL operons were positively regulated by the catabolite control protein [54]. Proteases linked to $c l p$ (ATP dependent) such as sub-unit $c l p P$ are highly active under general cell stress (heat, acid, ethanol, or p-coumaric acid). Similarly, a set of genes involved in tolerance to one or more environmental stresses was induced during the acid stress responses (class I and III stress response pathways) for $L b$. plantarum [52]. The involvement of the heat-shock proteins with the Clp proteins, pertinent to acid-mediated stress, is a feature across Lactobacillus species [43].

\section{Conclusions}

Exopolysaccharide biosynthesis is coordinated with the mutual activity of genes that participate in a multitude of cellular functions. Yeast presence in co-culture with lactic acid bacteria influenced metabolism and increased EPS production in a strain-dependent manner. Gene activation during the exponential phase and early stationary phase (from 6 to $12 \mathrm{~h}$ ) was determinant for EPS production by the L. rhamnosus strains in this study. L. rhamnosus RW-9595M demonstrated an important over-expression of target genes in co-culture compared to monoculture. This transcriptomic activity seems to be related to higher EPS production under acid stress conditions. Analysis of the gene co-expression networks has permitted the detection of key genes $(w z b)$ and the observation of direct correlations between the expression of genes of the EPS operons, sugar metabolism, amino acid biosynthesis, and lipid metabolism. This study contributes to a better knowledge of inter-kingdom interactions (bacteria - yeast) and the regulation of EPS biosynthesis. It also represents a step toward the development of bio-ingredients rich in polysaccharides. Cereal based products such as sourdough could benefit because the EPS produced in situ by starter or adjunct cultures of these strains can replace hydrocolloid additives. Future research must to be done to find out the influence of this EPS in water absorption of the dough, rheology and machinability, or particularly the prebiotic effects of foods containing EPS-containing ingredients.

Supplementary Materials: The following are available online at http://www.mdpi.com/2076-3417/9/19/4026/s1, Figure S1. Change in pH of medium fermented by L. rhamnosus R0011, ATCC 9595 and RW-9595M in mono (solid symbols) and co-culture (open symbols) fermentation. Figure S2. Acetic acid produced by Lactobacillus rhamnosus R0011, ATCC 9595 and RW-9595M in mono (m) and co-culture (c) at 24 and 48 h of fermentation. Table S1. Primer set used for the qPCR and PMA-qPCR analyses for Lactobacillus species. Table S2. Gene targets and parameters for RT-qPCR analysis by TaqMan for strains of L. rhamnosus and the assessment of specificity towards L. rhamnosus strains and S. cerevisiae. Table S3. Reference genes identified by the software geNorm for each time point of the fermentation for the three strains of L. rhamnosus, Table S4. Changes in the profile of phenolic acids by $L$. rhamnosus R0011, ATCC 9595 and RW-9595M in mono and co-culture during $48 \mathrm{~h}$ of fermentation.

Author Contributions: Conceptualization, D.R. and G.L.; Methodology, A.B.; Formal Analysis, A.B., G.L. and D.R.; Resources, G.L. and D.R.; Data Curation, G.L.; Writing - Original Draft Preparation, A.B.; Writing - Review \& Editing, G.L. and D.R.; Supervision, G.L.; Project Administration, G.L.; Funding Acquisition, G.L. and D.R.

Acknowledgments: This project was funded by Novalait and the Fonds de recherche du Quebec - Nature et Technologie (FRQNT).

Conflicts of Interest: A. Bertsch is employed by Biena. G. LaPointe and D. Roy declare no conflict of interest.

\section{References}

1. Ates, O. Systems biology of microbial exopolysaccharides production. Front. Bioeng. Biotechnol. 2015, 3, 200. [CrossRef] [PubMed]

2. Oleksy, M.; Klewicka, E. Exopolysaccharides produced by Lactobacillus sp.—Biosynthesis and applications. Crit. Rev. Food Sci. Nutr. 2018, 58, 450-462. [CrossRef] [PubMed]

3. Ruas-Madiedo, P.; Hugenholtz, J.; Zoon, P. An overview of the functionality of exopolysaccharides produced by lactic acid bacteria. Int. Dairy J. 2002, 12, 163-171. [CrossRef] 
4. Macedo, M.G.; Lacroix, C.; Gardner, N.J.; Champagne, C.P. Effect of medium supplementation on exopolysaccharide production by Lactobacillus rhamnosus RW-9595M in whey permeate. Int. Dairy J. 2002, 12, 419-426. [CrossRef]

5. Caggianiello, G.; Kleerebezem, M.; Spano, G. Exopolysaccharides produced by lactic acid bacteria: From health-promoting benefits to stress tolerance mechanisms. Appl. Microbiol. Biotechnol. 2016, 100, 3877-3886. [CrossRef] [PubMed]

6. Rahbar Saadat, Y.; Yari Khosroushahi, A.; Pourghassem Gargari, B. A comprehensive review of anticancer, immunomodulatory and health beneficial effects of the lactic acid bacteria exopolysaccharides. Carbohydr. Polym. 2019, 217, 79-89. [CrossRef] [PubMed]

7. Lynch, K.M.; Zannini, E.; Coffey, A.; Arendt, E.K. Lactic acid bacteria exopolysaccharides in foods and beverages: Isolation, properties, characterization, and health benefits. Annu. Rev. Food Sci. Technol. 2018, 9, 155-176. [CrossRef]

8. Salazar, N.; Gueimonde, M.; de los Reyes-Gavilán, C.G.; Ruas-Madiedo, P. Exopolysaccharides produced by lactic acid bacteria and bifidobacteria as fermentable substrates by the intestinal microbiota. Crit. Rev. Food Sci. Nutr. 2016, 56, 1440-1453. [CrossRef] [PubMed]

9. Sanalibaba, P.; Cakmak, G.A. Exopolysaccharides production by lactic acid bacteria. Appl. Microbiol. Open Access 2016, 2, 115. [CrossRef]

10. Peant, B. Comparative analysis of the exopolysaccharide biosynthesis gene clusters from four strains of Lactobacillus rhamnosus. Microbiology 2005, 151, 1839-1851. [CrossRef]

11. Van Calsteren, M.-R.; Pau-Roblot, C.; Bégin, A.; Roy, D. Structure determination of the exopolysaccharide produced by Lactobacillus rhamnosus strains RW-9595M and R. Biochem. J. 2002, 363, 7-17. [CrossRef] [PubMed]

12. Dupont, I.; Roy, D.; Lapointe, G. Comparison of exopolysaccharide production by strains of Lactobacillus rhamnosus and Lactobacillus paracasei grown in chemically defined medium and milk. J. Ind. Microbiol. Biotechnol. 2000, 24, 251-255. [CrossRef]

13. Bergmaier, D.; Champagne, C.P.; Lacroix, C. Exopolysaccharide production during batch cultures with free and immobilized Lactobacillus rhamnosus RW-9595M. J. Appl. Microbiol. 2003, 95, 1049-1057. [CrossRef] [PubMed]

14. Bader, J.; Mast-Gerlach, E.; Popović, M.K.; Bajpai, R.; Stahl, U. Relevance of microbial coculture fermentations in biotechnology: Coculture fermentations in biotechnology. J. Appl. Microbiol. 2010, 109, 371-387. [CrossRef] [PubMed]

15. Smid, E.J.; Lacroix, C. Microbe-microbe interactions in mixed culture food fermentations. Curr. Opin. Biotechnol. 2013, 24, 148-154. [CrossRef] [PubMed]

16. Goers, L.; Freemont, P.; Polizzi, K.M. Co-culture systems and technologies: Taking synthetic biology to the next level. J. R. Soc. Interface 2014, 11, 20140065. [CrossRef] [PubMed]

17. Bertrand, S.; Bohni, N.; Schnee, S.; Schumpp, O.; Gindro, K.; Wolfender, J.-L. Metabolite induction via microorganism co-culture: A potential way to enhance chemical diversity for drug discovery. Biotechnol. Adv. 2014, 32, 1180-1204. [CrossRef] [PubMed]

18. Di Cagno, R.; Pontonio, E.; Buchin, S.; De Angelis, M.; Lattanzi, A.; Valerio, F.; Gobbetti, M.; Calasso, M. Diversity of the lactic acid bacterium and yeast microbiota in the switch from firm- to liquid-sourdough fermentation. Appl. Environ. Microbiol. 2014, 80, 3161-3172. [CrossRef]

19. Cheirsilp, B.; Shimizu, H.; Shioya, S. Enhanced kefiran production by mixed culture of Lactobacillus kefiranofaciens and Saccharomyces cerevisiae. J. Biotechnol. 2003, 100, 43-53. [CrossRef]

20. Cheirsilp, B.; Radchabut, S. Use of whey lactose from dairy industry for economical kefiran production by Lactobacillus kefiranofaciens in mixed cultures with yeasts. New Biotechnol. 2011, 28, 574-580. [CrossRef]

21. Liu, C.; Hu, B.; Liu, Y.; Chen, S. Stimulation of nisin production from whey by a mixed culture of Lactococcus lactis and Saccharomyces cerevisiae. Appl. Biochem. Biotechnol. 2006, 129-132, 751-761. [CrossRef]

22. Tada, S.; Katakura, Y.; Ninomiya, K.; Shioya, S. Fed-batch coculture of Lactobacillus kefiranofaciens with Saccharomyces cerevisiae for effective production of kefiran. J. Biosci. Bioeng. 2007, 103, 557-562. [CrossRef] [PubMed]

23. Chanos, P.; Mygind, T. Co-culture-inducible bacteriocin production in lactic acid bacteria. Appl. Microbiol. Biotechnol. 2016, 100, 4297-4308. [CrossRef] [PubMed] 
24. Mendes, F.; Sieuwerts, S.; de Hulster, E.; Almering, M.J.H.; Luttik, M.A.H.; Pronk, J.T.; Smid, E.J.; Bron, P.A.; Daran-Lapujade, P. Transcriptome-based characterization of interactions between Saccharomyces cerevisiae and Lactobacillus delbrueckii subsp. bulgaricus in lactose-grown chemostat cocultures. Appl. Environ. Microbiol. 2013, 79, 5949-5961. [CrossRef] [PubMed]

25. Xie, N.; Zhou, T.; Li, B. Kefir yeasts enhance probiotic potentials of Lactobacillus paracasei H9: The positive effects of coaggregation between the two strains. Food Res. Int. 2012, 45, 394-401. [CrossRef]

26. Vorob'eva, L.I.; Khodzhaev, E.Y.; Rogozhin, E.A.; Cherdyntseva, T.A.; Netrusov, A.I. Characterization of extracellular yeast peptide factors and their stress-protective effect on probiotic lactic acid bacteria. Microbiology 2016, 85, 411-419. [CrossRef]

27. Desfossés-Foucault, É.; LaPointe, G.; Roy, D. Transcription profiling of interactions between Lactococcus lactis subsp. cremoris SK11 and Lactobacillus paracasei ATCC 334 during Cheddar cheese simulation. Int. J. Food Microbiol. 2014, 178, 76-86.

28. Rivière, A.; Gagnon, M.; Weckx, S.; Roy, D.; De Vuyst, L. Mutual cross-feeding interactions between Bifidobacterium longum subsp. longum NCC2705 and Eubacterium rectale ATCC 33656 explain the bifidogenic and butyrogenic effects of arabinoxylan oligosaccharides. Appl. Environ. Microbiol. 2015, 81, 7767-7781.

29. Ye, J.; Coulouris, G.; Zaretskaya, I.; Cutcutache, I.; Rozen, S.; Madden, T.L. Primer-BLAST: A tool to design target-specific primers for polymerase chain reaction. BMC Bioinform. 2012, 13, 134. [CrossRef]

30. Cerning, J.; Bouillanne, C.; Landon, M.; Desmazeaud, M. Isolation and characterization of exopolysaccharides from slime-forming mesophilic lactic acid bacteria. J. Dairy Sci. 1992, 5, 692-699. [CrossRef]

31. Dubois, M.; Gilles, K.; Hamilton, J.K.; Rebers, P.A.; Smith, F. A colorimetric method for the determination of sugars. Nature 1951, 168, 167. [CrossRef] [PubMed]

32. Bustin, S.A.; Benes, V.; Garson, J.A.; Hellemans, J.; Huggett, J.; Kubista, M.; Mueller, R.; Nolan, T.; Pfaffl, M.W.; Shipley, G.L.; et al. The MIQE Guidelines: Minimum information for publication of quantitative real-time PCR experiments. Clin. Chem. 2009, 55, 611-622. [CrossRef] [PubMed]

33. Vandesompele, J.; De Preter, K.; Pattyn, F.; Poppe, B.; Van Roy, N.; De Paepe, A.; Speleman, F. Accurate normalization of real-time quantitative $R T-P C R$ data by geometric averaging of multiple internal control genes. Genome Biol. 2002, 3. [CrossRef] [PubMed]

34. Pfaffl, M.W. Quantification strategies in real-time PCR. In The Real-Time PCR Encyclopedia A-Z of Quantitative PCR; Bustin, S.A., Ed.; National University International: La Jolla, CA, USA, 2004; pp. 87-120.

35. Shannon, P. Cytoscape: A software environment for integrated models of biomolecular interaction networks. Genome Res. 2003, 13, 2498-2504. [CrossRef] [PubMed]

36. Liseron-Monfils, C.; Ware, D. Revealing gene regulation and associations through biological networks. Curr. Plant Biol. 2015, 3-4, 30-39. [CrossRef]

37. Wang, P.; Lü, J.; Yu, X. Identification of important nodes in directed biological networks: A network motif approach. PLoS ONE 2014, 9, e106132. [CrossRef] [PubMed]

38. Niwa, T.; Doi, U.; Kato, Y.; Osawa, T. Antioxidative properties of phenolic antioxidants isolated from corn steep liquor. J. Agric. Food Chem. 2001, 49, 177-182. [CrossRef]

39. Suharja, A.A.S.; Henriksson, A.; Liu, S.-Q. Impact of Saccharomyces cerevisiae on viability of probiotic Lactobacillus rhamnosus in fermented milk under ambient conditions: Impact of yeast on probiotics. J. Food Process. Preserv. 2014, 38, 326-337. [CrossRef]

40. Tsai, Y.-K.; Lin, T.-H. Sequence, organization, transcription and regulation of lactose and galactose operons in Lactobacillus rhamnosus TCELL-1. J. Appl. Microbiol. 2006, 100, 446-459. [CrossRef] [PubMed]

41. Shang, Y.; Zeng, Y.; Zhu, P.; Zhong, Q. Acetate metabolism of Saccharomyces cerevisiae at different temperatures during lychee wine fermentation. Biotechnol. Biotechnol. Equip. 2016, 30, 512-520. [CrossRef]

42. Bove, C.G.; Angelis, M.D.; Gatti, M.; Calasso, M.; Neviani, E.; Gobbetti, M. Metabolic and proteomic adaptation of Lactobacillus rhamnosus strains during growth under cheese-like environmental conditions compared to de Man, Rogosa, and Sharpe medium. Proteomics 2012, 12, 3206-3218. [CrossRef] [PubMed]

43. De Angelis, M.; Calasso, M.; Cavallo, N.; Di Cagno, R.; Gobbetti, M. Functional proteomics within the genus Lactobacillus. Proteomics 2016, 16, 946-962. [CrossRef] [PubMed]

44. Lazzi, C.; Turroni, S.; Mancini, A.; Sgarbi, E.; Neviani, E.; Brigidi, P.; Gatti, M. Transcriptomic clues to understand the growth of Lactobacillus rhamnosus in cheese. BMC Microbiol. 2014, 14, 28. [CrossRef] [PubMed]

45. Wolfe, A.J. The Acetate Switch. Microbiol. Mol. Biol. Rev. 2005, 69, 12-50. [CrossRef] [PubMed] 
46. Filannino, P.; Gobbetti, M.; De Angelis, M.; Di Cagno, R. Hydroxycinnamic acids used as external acceptors of electrons: An energetic advantage for strictly heterofermentative lactic acid bacteria. Appl. Environ. Microbiol. 2014, 80, 7574-7582. [CrossRef] [PubMed]

47. Filannino, P.; Bai, Y.; Di Cagno, R.; Gobbetti, M.; Gänzle, M.G. Metabolism of phenolic compounds by Lactobacillus spp. during fermentation of cherry juice and broccoli puree. Food Microbiol. 2015, 46, 272-279. [CrossRef] [PubMed]

48. Filannino, P.; Di Cagno, R.; Gobbetti, M. Metabolic and functional paths of lactic acid bacteria in plant foods: Get out of the labyrinth. Curr. Opin. Biotechnol. 2018, 49, 64-72. [CrossRef] [PubMed]

49. Yamasaki-Yashiki, S.; Sawada, H.; Kino-Oka, M.; Katakura, Y. Analysis of gene expression profiles of Lactobacillus paracasei induced by direct contact with Saccharomyces cerevisiae through recognition of yeast mannan. Biosci. Microbiota Food Health 2017, 36, 17-25. [CrossRef]

50. Boels, I.C.; van Kranenburg, R.; Kanning, M.W.; Chong, B.F.; de Vos, W.M.; Kleerebezem, M. Increased exopolysaccharide production in Lactococcus lactis due to increased levels of expression of the NIZO B40 EPS gene cluster. Appl. Environ. Microbiol. 2003, 69, 5029-5031. [CrossRef]

51. Poger, D.; Mark, A.E. A Ring to Rule Them All: The effect of cyclopropane fatty acids on the fluidity of lipid bilayers. J. Phys. Chem. B 2015, 119, 5487-5495. [CrossRef] [PubMed]

52. Huang, R.; Pan, M.; Wan, C.; Shah, N.P.; Tao, X.; Wei, H. Physiological and transcriptional responses and cross protection of Lactobacillus plantarum ZDY2013 under acid stress. J. Dairy Sci. 2016, 99, 1002-1010. [CrossRef] [PubMed]

53. Duary, R.K.; Batish, V.K.; Grover, S. Expression of the atpD gene in probiotic Lactobacillus plantarum strains under in vitro acidic conditions using RT-qPCR. Res. Microbiol. 2010, 161, 399-405. [CrossRef] [PubMed]

54. Castaldo, C.; Siciliano, R.A.; Muscariello, L.; Marasco, R.; Sacco, M. CcpA affects expression of the groESL and dnaK operons in Lactobacillus plantarum. Microb. Cell Factories 2006, 5, 35. [CrossRef] [PubMed]

(C) 2019 by the authors. Licensee MDPI, Basel, Switzerland. This article is an open access article distributed under the terms and conditions of the Creative Commons Attribution (CC BY) license (http://creativecommons.org/licenses/by/4.0/). 